\title{
Dimensions of Ignorance: Discourses and Practices of Obstetrics
}

Less than a year after Schweitzer's death, Guy Barthélemy published an extended 'letter' addressed to his former employer. In this thoughtful book, Barthélemy thanked Schweitzer for being an inspiration to him and recalled the following episode from a stay at the hospital in 1960:

I remember that surreal night when, in the pharmacy, we watched a film on atomic war, while an operation took place in the next room. The coincidence was disturbing. From the United States, you had received a copy of the film 'on the beach', telling a story about the end of humanity following a nuclear conflict. A projector had been installed at one end of the room and the curtains of a consulting space served as a screen. [...] In the middle of the film, some members of the audience started to move around. A cesarean section had to be performed in the operating area next door. Greet and a nurse worked marching like ghosts in the glow of the projector, arms raised so as not to contaminate their sanitized hands. Each time, on their white backs, you could see for a few seconds a woman's face shaking or a submarine diving. It was much more hallucinating than the, still atrocious, subject of the film by itself. What was the sick woman in childbirth to be thinking, in the midst of those strange cries that resonated, two steps away, to announce the end of the world?

This account raises key topics concerning maternity care and obstetrical practices at the Albert Schweitzer Hospital. It is an unusual description, for it places the act of giving birth, which received comparatively little attention in the daily work at the hospital, in the spotlight. Cesareans, however, were an area of significant discursive concern in the sources. They occurred relatively frequently in comparison to other hospitals in Gabon, but remained rare in relation to the number of births categorized as 'normal'. Unusually, the outside world, here in the form of the nuclear threat, intrudes on hospital life during this screening. While officials and missionaries in many colonies targeted mothers as key to solving the supposed wider societal issues of depopulation

1 Barthélemy, Lettre à Albert Schweitzer, 79-80. 
and to reconfiguring conceptions of domesticity, doctors and nurses at Schweitzer's hospital generally ignored the concerns of these external actors.

Such dynamics of 'deliberate and inadvertent neglect' 2 are an excellent lens through which to study the hospital in the context of colonial medical trends and local practices alike. The analytical framework of agnotology, the study of ignorance, enables the historian to write about that which did not occur or which does not appear in the sources. It exposes the connections between inattention and knowledge and how these influenced practices. An analysis of ignorance thus aids to understand why staff shaped obstetrical practice at the Albert Schweitzer Hospital to take on a, what they perceived to be exclusively medical, role as a curative service.

Depopulation, Domesticity, Ignorance: Framing Maternity Care in Colonial Africa

A number of practices around childbirth are common to all types of hospitals throughout colonial Africa. One that was popular with local residents was the distribution of extra-medical items, such as soap or clothing. ${ }^{3}$ A more contested practice was the introduction of lying to replace sitting as the standard birth position. ${ }^{4}$ As well as pre- and postnatal consultations, hospitals usually offered curative services. These treatments for mother and child were often the most in-demand services at maternity centers in Africa. ${ }^{5}$

Just as in most African societies, childbirth in colonial hospitals was a predominantly or even exclusively female domain. This was widely accepted by the parties involved in medical policy-making, including male and female colonial officials, medical personnel, and missionaries as well as local male leaders, midwives, and mothers. ${ }^{6}$ In Gabon too, as the Service de la Santé's 1935

2 Proctor, 'Agnotology. A Missing Term to Describe the Cultural Production of Ignorance (and Its Study)', 8.

3 Some colonial women associations, often responsible for providing these services, even suspected that the gifts constituted the main reason why women chose to come to maternity centers. See: Hunt, 'Le Bebe en Brousse', 422; Hugon, 'La redéfinition de la maternité en Gold Coast', $157-58$.

4 In colonial Ghana, this had been accepted by most local mothers by the 1940s. See: Hugon, 'Les sages-femmes africaines en contexte colonial', 186. In French West Africa, this was the case only from the early 196os. See: Barthélémy, 'Sages-femmes africaines diplômées en AOF', 138.

5 Addae, The Evolution of Modern Medicine in a Developing Country, 230; Allman, 'Making Mothers', 32; Van Tol, 'Mothers, Babies, and the Colonial State', 122.

6 Thomas, Politics of the Womb; Bruchhausen, Medizin zwischen den Welten, 449; Kumwenda, The Development of UMCA Medical Work in Northern Rhodesia, 9. 
annual report emphasized, 'each hospital has its own maternity ward with the female staff indispensable for its operation. ${ }^{7}$ This was also the case at the Albert Schweitzer Hospital; however, obstetrical encounters occurred exclusively at the clinic and never itinerantly in the wider community. Thus another typical feature of colonial maternity care is lacking: the interaction between a local birth attendant and a biomedically trained African or European midwife. ${ }^{8}$

Biomedical maternity care in colonial Africa has usually been understood in relation to one or two dominant discourses. The first played on a fear of depopulation and resulting economic inefficiency. Meredeth Turshen points out that in 'efforts to control rates of population growth', the disparate levels on which colonial policy operated can be observed. 'At one extreme were microlevel attempts to change breast-feeding practices, for example, and at the other extreme were macrolevel policies such as taxation', she notes. ${ }^{9}$ Medical doctors were crucial in laying the groundwork for these measures. From the 1910s, physicians in different African colonies conducted interviews with mothers to find out more about the number and survival rate of their children. These surveys were often built on a weak scientific foundation, even by the standards of the day, but provided the basis of official demographic statistics. ${ }^{10}$

In France, officials had been concerned about depopulation since the start of the country's colonial expansion in the late nineteenth century. ${ }^{11}$ In the interwar period, European powers believed that low fertility rates, poor maternity services, and emigration to neighboring territories had led to, among other challenges, a shortage of labor in many colonies. ${ }^{12}$ The equatorial region spanning from Uganda to Cameroon was of particular concern in this respect. ${ }^{13}$ French colonial documents from the 1920 s relating to AEF 'are filled with impressions of population decline, high mortality, and impending demographic

$7 \quad$ 'Rapport médical sur le fonctionnement durant l'année 1935 des services sanitaires et médicaux civils de l'Afrique Equatoriale Francaise'. ZK 005-121, SHD.

Hunt, A Colonial Lexicon, 157; Kalusa and Vaughan, Death, Belief and Politics in Central African History, 303; Hugon, 'Les sages-femmes africaines en contexte colonial', 187; Cole, 'Engendering Health', 114.

9 Turshen, 'Reproducing Labor', 231.

10 Coghe and Widmer, 'Colonial Demography'. For an example of such a survey, see: Hunt, $A$ Nervous State, chapter 4.

11 Pedersen, 'Special Customs', 47.

12 Cordell, Ittman, and Maddox, 'Counting Subjects'. Current research suggests that anxieties about depopulation were exaggerated because 'African growth rates for the nineteenth and early twentieth centuries were lower than previously thought, with the result that African population in the nineteenth and early twentieth centuries were considerably higher than previously thought'. Manning, 'African Population', 264.

Hunt, A Nervous State, 12-14. 
disaster. ${ }^{14}$ In the 1950 , the area around Lambaréné was considered to be particularly affected by these issues, with the blame placed on either 'the extreme simplicity of morals ${ }^{15}$ or venereal diseases. ${ }^{16}$ Numerous local elders throughout the equatorial zone shared these concerns, including among the Fang in Gabon. ${ }^{17}$ Schweitzer and his staff, however, displayed little awareness of these ongoing debates.

The second main discursive pillar of colonial maternity care envisioned a new domesticity for Africans. Colonial officials and missionaries aimed at redefining and expanding the role of African women as mothers and heads of the household. It was hoped that they could thus serve not only as advocates for better health by improving family hygiene and nutrition, but also as conveyors of Christian values and Western ideas about gender and domesticity. To this end, many of the services offered at infant and maternal healthcare facilities run by missions and colonial governments involved raising awareness about preventive healthcare. ${ }^{18}$ These efforts culminated in a joint transnational government-missionary conference on the African child, which was hosted in Geneva in 1931. Participants 'avoided the obvious issues of economic exploitation and political expediency' and reassured themselves that 'social and educative solutions' worked best for the welfare of African women and children. ${ }^{19}$ In Gabon too, missions prioritized the refiguring of local family structures and gender roles, making a pronounced effort to recruit girls for attending their schools. ${ }^{20}$ Once more at the Albert Schweitzer Hospital, however, such issues were rarely addressed.

Colonial ideals of domesticity were connected to a belief in the superiority of European values. The supposed ignorance of local mothers was a recurring theme invoked to justify biomedical and pedagogical interventions all over

14 Cinnamon, 'Counting and Recounting', 131. See also: Headrick, Colonialism, Health and Illness in French Equatorial Africa, 104-5.

15 Sautter, De l'Atlantique au fleuve Congo, 800-801. Sautter, a geographer, found that women in the Lambaréné area had much fewer pregnancies than women in other parts of rural Gabon.

16 Fernandez, Bwiti, 163. In his endnote (621), Fernandez refers to a wHo research team that he met that had found 'evidence of venereal infection' in 30-40 percent of the population in northern Gabon.

17 Giles-Vernick, Cutting the Vines of the Past, 118. Songs from the region reflected these anxieties. See: Hunt, A Nervous State, 128. On the Fang specifically, see: Balandier, Sociologie actuelle de l'Afrique Noire, 90-91; Fernandez, Bwiti, 162.

18 Manderson, 'Women and the State', 171; Van Tol, 'Mothers, Babies, and the Colonial State', 124; Hugon, 'La redéfinition de la maternité en Gold Coast', 157-58.

19 Allman, 'Making Mothers', 25.

20 Mebiame Zomo, 'Le travail des missions chrétiennes au Gabon pendant la colonisation', 63-64; Mekodiomba, 'Rôle et influence des églises missionnaires dans la mission civilisatrice au Gabon', 88-89. 
Africa and beyond. ${ }^{21}$ Various scholars have drawn attention to the fact that very similar discourses on maternal ignorance were circulating in Europe from roughly 1900 to the beginning of World War Two, ${ }^{22}$ which underlines that discussions on proper maternity care did not only circle around race, but also gender and class.

In order to further pursue this chapter's central focus on the production and accusation of ignorance, other key aspects of maternity care in Africa have to be neglected, most notably issues of medicalization and gender. Ignorance operates on a number of different levels. On the one hand European staff at the Albert Schweitzer Hospital blamed Africans for being ignorant of proper biomedical practices, an attitude that they shared with missionaries and colonial government officials. On the other hand, staff ignored not only the typical colonial discourses on maternity care outlined above, but also the circumstances and practices of local mothers. Constructing such arguments 'about who is ignorant of what' is problematic, yet unavoidable when studying ignorance. ${ }^{23}$ This chapter also demonstrates how difficult it is for the historian to draw a clear distinction between 'intentional and unintentional not-knowing', a differentiation typically made in ignorance studies. ${ }^{24}$

The favoring of certain types of knowledge over others is a key feature of colonialism. Londa Schiebinger writes of 'a kind of cultured apathy or cultivated disinterest', ${ }^{25}$ which Ann Laura Stoler terms 'the averted gaze. ${ }^{26}$ Wenzel Geissler has introduced the term 'unknowing' in the context of present-day North-South cooperation in scientific knowledge production. Field scientists practicing in the South, 'invest effort in "unknowing" difference'. They neither 'deny, hide, nor ignore' practices or realities that are strange or different in their view, but they refrain from establishing difference as 'explicit truth'. Such a process seems necessary to render scientific endeavors feasible. ${ }^{27}$ Following Geissler's definition I retrace how biomedical personnel devoted effort to unknowing difference in order to practice their idea of medicine.

21 Greenwood, 'The Colonial Medical Service and the Struggle for Control', 94-95; Havik, 'Public Health, Social Medicine and Disease Control'; Jolly, 'Maternities and Modernities, Introduction'; Kanogo, 'The Medicalization of Maternity in Colonial Kenya', 85. The key text being: Davin, 'Imperialism and Motherhood'. See also: Manderson, 'Women and the State', 174; Kalusa and Vaughan, Death, Belief and Politics in Central African History, 300; Van Tol, 'Mothers, Babies, and the Colonial State', 124.

23 Smithson, 'Social Theories of Ignorance', 210. See also: Groß and McGoey, 'Routledge International Handbook of Ignorance Studies, Introduction'.

24 Dilley and Kirsch, 'Regimes of Ignorance', 1. See also: Proctor, 'Agnotology. A Missing Term to Describe the Cultural Production of Ignorance (and Its Study)', 6-7.

25 Schiebinger, 'West Indian Abortifacients and the Making of Ignorance', 156.

26 Stoler, Along the Archival Grain, 255.

27 Geissler, 'Public Secrets in Public Health', 17. 
Schweitzer and his staff followed the colonial logic by disregarding local maternity practices. However, while they simply ignored them, missionaries and colonial officials dismissed them as invalid or dangerous. Schweitzer and his staff intentionally refrained from participating in the colonial discussions on depopulation and domesticity because they were following a different agenda. Schweitzer did not intend to contribute towards ensuring an adequate supply of healthy laborers or educating a cohort of housewives, but instead envisaged the hospital as a shining example of his ethics. These motivations shaped the production of ignorance at the hospital and thus its medical practices. Murray Last has raised the question of how much people know, and care to know, about their own medical culture and how much a practitioner needs to know in order to practice medicine.' ${ }^{28} \mathrm{He}$ concludes that 'a segment of medical culture can flourish in seeming anarchy', in part because of 'people not knowing and not wishing to know' ${ }^{29}$ In at least the case of maternity care at the Albert Schweitzer Hospital, these observations are valid for patients and practitioners alike.

\section{Maternity Services in Colonial Gabon and at the Albert Schweitzer Hospital}

Infant mortality was the cause of considerable concern in Gabon. Europeans frequently blamed maternal ignorance for premature deceases. Nevertheless, as Rita Headrick writes, 'the problems of mothers and babies were not considered important enough for the government to divert resources from other areas. This responsibility could be left to colonial wives' ${ }^{30}$ In the 193os, European women living in Libreville ran the privately financed 'Berceau Gabonais', which distributed soap, clothes, and canned milk among mothers-to-be. Together with a community health worker who was trained by the midwife in Libreville, they encouraged African women to undergo prenatal consultations and to deliver their babies at hospitals. Their efforts did not meet with much success; the most in-demand services offered by the Berceau were curative consultations for infants. ${ }^{31}$ As late as in the mid-1950s, when the French colonial government increased its efforts to reduce child mortality in Gabon, officials still based their interventions on discourses that assumed ignorance among local mothers and families. ${ }^{32}$

28 Last, 'The Importance of Knowing about Not Knowing', 393.

29 Ibid., 403.

30 Headrick, Colonialism, Health and Illness in French Equatorial Africa, 151.

31 Ibid., 271; Mabika, 'Médicalisation de l'Afrique centrale', 339.

32 Tezi, 'Une approche socio-historique de l'avènement de la pédiatrie au Gabon', 114-18. 


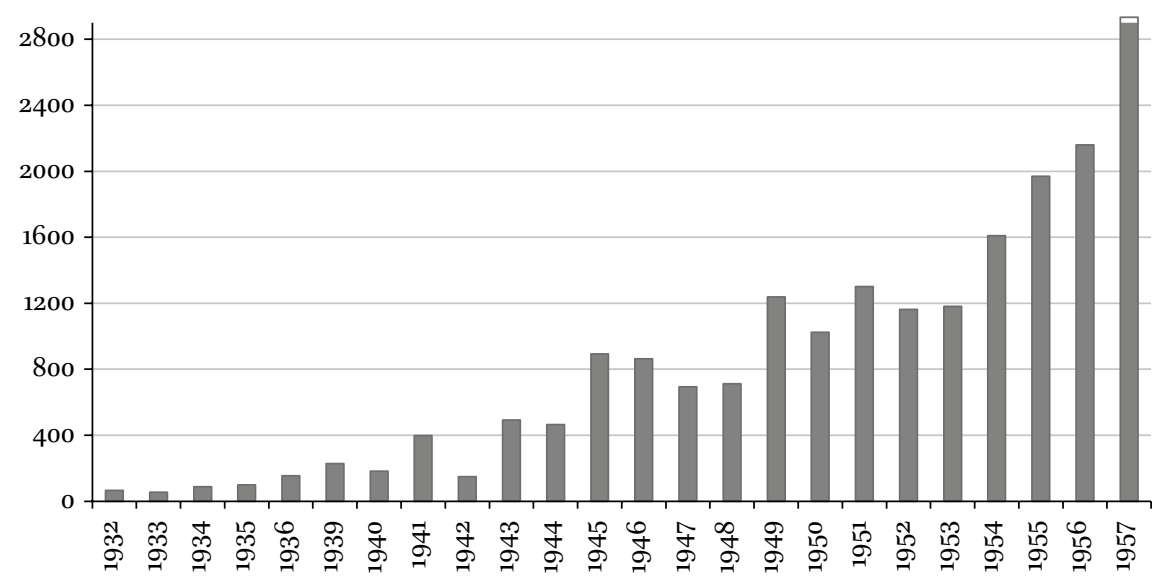

FIGURE 7 Deliveries at government clinics in Gabon

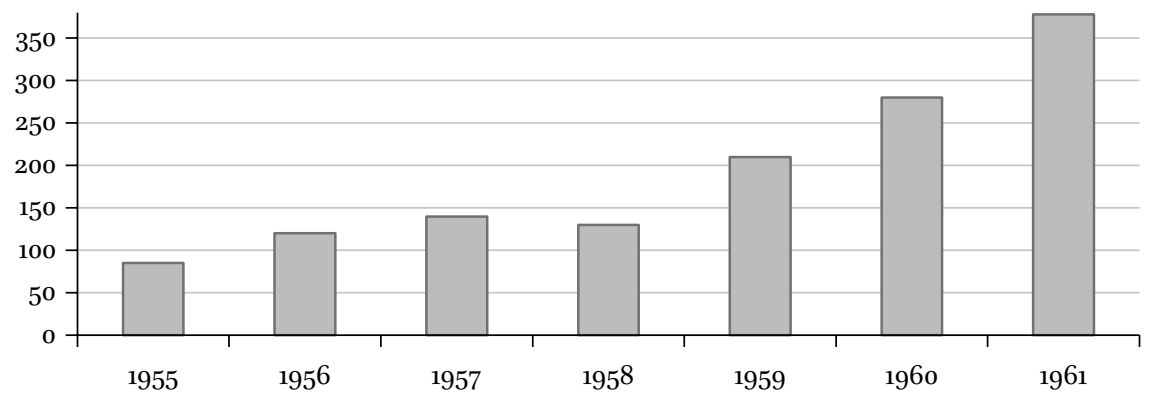

FIGURE 8 Deliveries at Lambaréné government hospital

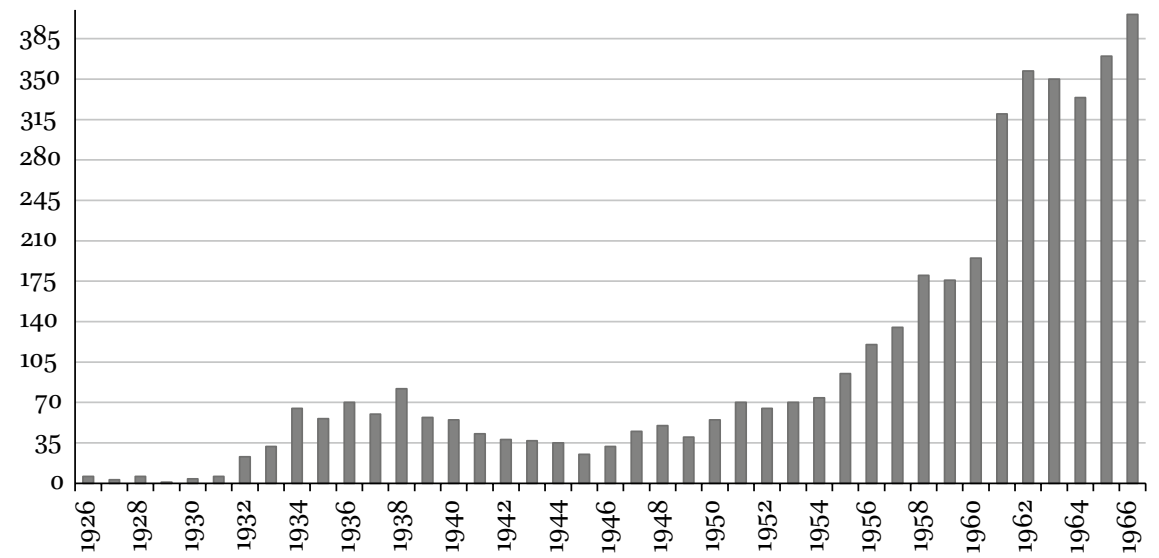

FIGURE 9 Deliveries at the Albert Schweitzer Hospital 


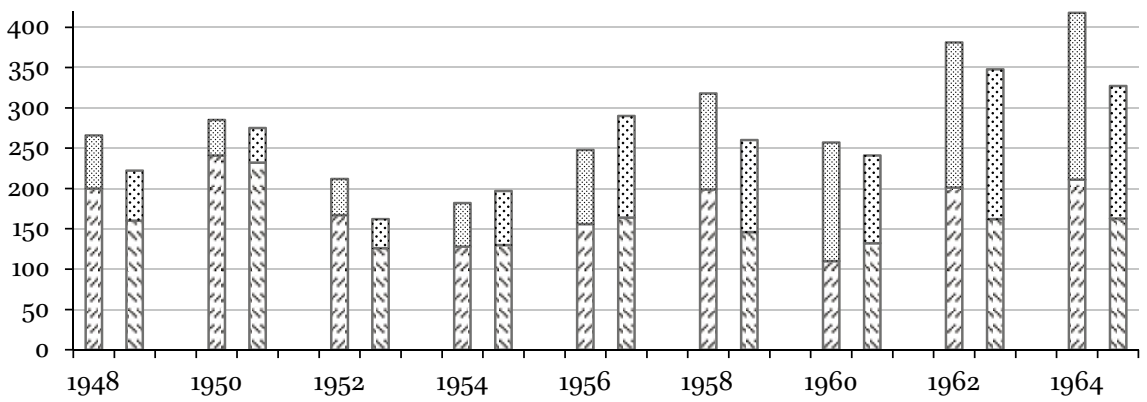

W Women staying at the end of September a Men staying at the end of September $\square$ Women staying at the end of April 四 Men staying at the end of April

FIGURE 10 Gender ratio of inpatients at the Albert Schweitzer Hospital

The first maternity ward run by the colonial government in Gabon was established at the hospital in Libreville before World War One. It was usually staffed by European midwives, and from 1938 also by African matrons. Until 1960, it had no doctor who had been trained in obstetrics. ${ }^{33}$ In 1934, the hospital hosted sixty-two of the eighty-eight deliveries performed at all government health facilities in Gabon. ${ }^{34}$ One year later, plans to improve maternal and infant care while restructuring AEF's 'Assistance Médicale et Rurale' were formulated, but these proved to be too ambitious and were never realized. ${ }^{35}$ Hines Mabika highlights that prenatal consultations in Gabonese hospitals rose together with the number of deliveries from 1939 to 1941, but much less drastically from 1943 to 1945 when the number of hospital births substantially increased again. ${ }^{36}$

All the figures on delivery numbers contain considerable uncertainty and only serve to provide a broad picture. Figure 7 illustrates the total number of recorded deliveries at all government clinics in Gabon from 1932 to $1957 .^{37}$ A sharp increase to almost 9oo deliveries occurred in 1945, when there was a total of eight maternity wards in Gabon. By 1951, there were twelve in the territory. Four years later, the number of deliveries had risen considerably again, even though no additional wards had been opened; the existing units provided

33 Mabika, 'Médicalisation de l'Afrique centrale', 298, 323.

34 'Rapport Annuel du Service de Santé de la Colonie du Gabon 1934'. ZK 005-127, SHD.

35 Mabika, 'Médicalisation de l'Afrique centrale', 337-39.

36 Ibid., 325 .

37 No data could be found for 1937 and 1938. See the annual reports of the Service de Santé for AEF and for Gabon: ZK oo5- 121(1933-36)/16o(1939-44)/089(1945-47)/o91(194950)/o92(1951)/o97(1952)/o93(1952-53)/o16(1954-55)/o95(1955-56), SHD; ZK oo5-127(1931$34) / 128(1946-51) / 005\left(1945,195^{2-57)}\right.$, SHD. 
a total of 177 beds. ${ }^{38}$ It is unclear how many wards were in operation in 1957, when the colonial records end and a sudden rise in hospital deliveries occurred. One explanation for this increase is that in the course of the Service de la Santé's restructuring in that year, birth certificates became obligatory for all Gabonese newborns. ${ }^{39}$

The maternity ward at the government clinic in Lambaréné was established in 1945, twelve years after that at the Albert Schweitzer Hospital. ${ }^{40}$ According to the calculations of the colonial administration, the demand for deliveries in the Lambaréné Subdivision was sufficiently high to support two maternity clinics. A 1956 evaluation concluded that an ideal maternity ward would host 90 to 240 births per year and serve an area with a twenty-kilometer radius and 3,000 to 8,00o inhabitants. ${ }^{41}$ In comparison, the population of the Lambaréné Subdivision was an estimated 17,00o people at the time. ${ }^{42}$ Figure 8 illustrates the numbers of deliveries at the government facility in Lambaréné for the period from 1955 to $1961 .{ }^{43}$ Unlike in the rest of Gabon, there was no abrupt increase in births in 1957, which suggests that the legal requirement to obtain a birth certificate is not sufficient to explain African mothers' sudden motivation for delivering their babies at hospitals. The steep rise after independence, in contrast, parallels the trend at Schweitzer's hospital across the river, a fact which refutes simple explanations based on demand and supply, instead suggesting external push factors. The Gabonese state paid for hospital births in the early 196os, something never referred to before. ${ }^{44}$ During this short period of data overlap, approximately the same number of babies was delivered at the

38 Annual reports of the Sérvice de la Santé for Gabon, ZK 005-128 (1946, 1951), ZK 005-005 (1955), SHD.

39 Mabika Ognandzi, Médicaliser l'Afrique, 242-47. Mabika does not explicitly refer to the new birth certificate requirement, but outlines the restructuring of the service.

40 In the 1946 annual report of the Service de Santé for Gabon, Lambaréné is not included on the list of 'Maternités'. According to the 1951 report, the maternity ward there consisted of two structures with a total of five rooms for patients. The 1954 report states that the ward at Lambaréné hospital had been constructed in 1945 and comprised three rooms, each with four beds, ZK 005-128 (1946, 51), ZKo05-005 (1954), SHD.

41 'Rapport Annuel du Service de Santé de la Colonie du Gabon 1956', ZK 005-005, SHD. The report also claims that women favored coming for pre- and postnatal consultations. The main aim of the report was to calculate the cost of a hospital birth for the state, which it estimated at 5,200 francs.

42 The 1953 Rapport Annuel du Service de Santé de la Colonie du Gabon lists the population at 17,249, ZK 005-005, SHD.

43 No numbers could be obtained for earlier years. The data is from the 1961 annual report of the Centre Médical de Lambaréné, $\mathrm{PR}(\mathrm{H}), 1 \mathrm{H}$ 226.1, ANG.

44 Müller, ‘5o Jahre Albert-Schweitzer-Spital', 26; Stocker, 'Diary 1961-63', 7; Interview Munz and Munz. 
government hospital as at Schweitzer's hospital, but the numbers of surgical interventions were up to ten times higher at the latter. ${ }^{45}$ The tempting argument that pregnant women only chose the Albert Schweitzer Hospital to give birth because it did not involve campaigns on how to be a good housewife and deliver more children is thus difficult to uphold.

Figure 9 illustrates the approximate number of deliveries by African mothers at the Albert Schweitzer Hospital. ${ }^{46}$ Prior to 1932, no more than six children were ever born to African women in a single year. In that year, a drastic increase occurred, with twenty-three births recorded. Within the following two years, the number of deliveries almost tripled, possibly due to the newly built maternity ward established as a separate unit in 1933 (see Illustration 18). Previously, women in childbirth had been accommodated alongside surgical patients, whose numbers had also increased. ${ }^{47}$ The eight beds in the small unit were well-occupied throughout the decade. ${ }^{48}$ The head of AEF's Service d'Hygiène, who was otherwise rather hostile towards Schweitzer and his hospital, was impressed about the high number of childbirths there. ${ }^{49}$

Like overall patient numbers and the number of surgical cases, the number of deliveries dropped during World War Two; not until 1955, when fifteen beds were provided in the maternity ward, ${ }^{50}$ did annual childbirths significantly

45 The government hospital performed 68 operations in 196o, while the surgeons at Schweitzer's hospital conducted 517 . One year later, this ratio stood at $58: 800$. This data is from the 1960 and 1961 annual reports of the Centre Médical de Lambaréné, $\mathrm{PR}(\mathrm{H}), 1 \mathrm{H}$ 226.1, ANG.

46 The data for the years $1926-38,1942-43$, 1946, and 1966 are taken from 'Statistiques de l'Hôpital'. L - A - S1-3, AMs. Birth protocols are available for the years 1938-41, 1953-54, 1959-64. L - P - A1-8, AMs. The 1955 annual report is held at: PR(H), 1 H 235.4, ANG. Dr. Greet van der Kreek provides the number for 1956 in a letter to Schweitzer dated 18 July 1957 (held at AMs). The other statistics (for the years 1943-45, 1947-52, 1957-58, 1965) are taken from: Munz, Mit dem Herzen einer Gazelle und der Haut eines Nilpferds, 199. Munz provides a rather imprecise graph, the exact numbers in which are difficult to render. He claims to have taken these figures from 'patient records and operation books'. For the years for which I had data, my numbers correlated well with those provided by Munz. This was not the case, however, for the number of surgical operations, which he also lists in the same graph.

47 Schweitzer, 'Briefe aus dem Lambarene Spital Februar 1934', 4. The maternity ward at Schweitzer's hospital was not mentioned in the annual report of the Service de la Santé for 1932, but in that of the following year. It reportedly consisted of three rooms with two beds and two rooms with one bed each, ZK 005-127, SHD.

48 Schweitzer, 'Briefe aus dem Lambarene Spital Januar 1935', 3; 'Briefe aus dem Lambarene Spital Mai 1937', 3 .

49 Goldschmid to Schweitzer, 10 October 1936, Ams.

50 This is indicated in one of the few annual reports (1955) sent by Schweitzer to the colonial administration after the outbreak of World War Two, PR(H), 1 H 235.4, ANG. 


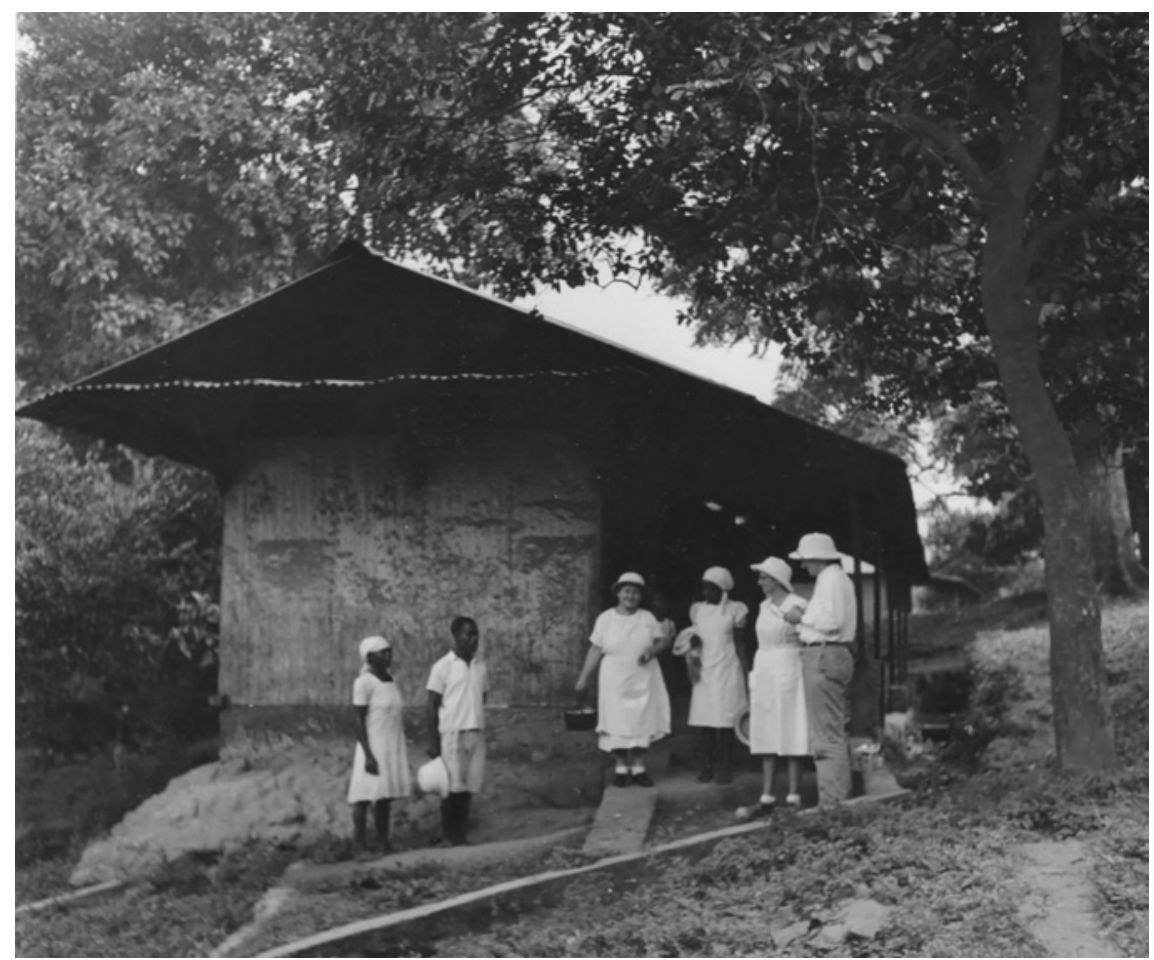

ILLUSTRATION 18 Staff in front of the hospital's maternity ward, ca. 1934

(C) ARChives CENTRALES ALBERT SCHWEITZER GUNSBACH

outnumber pre-war levels. The increase in the following years is slightly delayed in comparison to the overall numbers for Gabon. After independence, another significant rise correlates with an increase in overall admissions and the growing number of deliveries at the government hospital. In 1960, a new building was constructed with thirty-five beds for mothers-to-be. ${ }^{51}$ The new ward had 'a dirt floor' and, one year later, 'its aluminum walls (were) already darkened from the smoke of cooking fires', as the visiting US American medical student Eugen Schoenfeld noted. ${ }^{52}$

With the rise in births, the number of female patients at the hospital grew, as Figure 10 demonstrates. In the mid-1950s, women accounted for approximately 25 percent of all inpatients. After 1960, half of them were female. On the

$51 \quad$ Siefert, Meine Arbeitsjahre in Lambarene 1933-1935, 178.

52 Schoenfeld, 'A Summer at Dr. Schweitzer's Hospital (Draft)', AMs, 7. A modified and considerably shortened version of this text was published in the Journal of Medical Education, Vol. 36, March 1961. 
surface, it may appear that the rise in female patients was mainly due to the increasing number of babies being delivered at the hospital. However, the appels mensuels reveal that not only did births steadily increase, but so did 'gynecologic affections' in general. This was a minor category of illness in 1954, but in 1962 was the diagnosis most frequently given to inpatients after hernias and none at all. ${ }^{53}$ Thus, more and more women attended the hospital to treat common afflictions.

Maternity care was of minor concern at the Albert Schweitzer Hospital, at least until the mid-1950s. As Figure 9 shows: before 1955, there had rarely been more than seventy births per year. When compared to surgery, the hospital's top priority, the number of deliveries had always been much lower, with the notable exception of during World War Two, when the number of births equaled the number of operations performed. Usually, the number of births was about five times less than the number of operations. However, after 1957, there were only four times more operations than births, and after 1961 the ratio was at roughly three to one.

Another manifestation of the marginal status of maternity care at the hospital in comparison to that of other services are the comparatively few references to it in the sources and the fact that the doctors did not find it worthy of more than passing mention it in their reports. While surgery, for example, frequently provided evidence of spectacular pathologies, deliveries - even when conducted by cesarean - seemed comparatively uninteresting. From the strictly medical perspective of Schweitzer and his staff, who did not attach any wider meaning to maternity care, obstetrics remained insignificant at the hospital until the number of deliveries increased. When Dr. Ilse Schnabel presented a portrait of the hospital in one of the main Swiss medical journals in 1936, over a quarter of her article focused on surgery, but she did not mention maternity services at all. ${ }^{54}$ Her neglect of the topic is remarkable, because she wrote her article not long after the hospital's maternity services had been expanded for the first time. Twenty-seven later, Dr. Rolf Müller dedicated only three pages to obstetrics in a similar article, in comparison to almost ten on surgery. ${ }^{55}$ Schweitzer himself considered obstetrics not worthy of a mention when he discussed the services offered at the hospital in $1948 .^{56}$ Although he and his staff may have thought it unnecessary to inform their readers about a fairly routine service such as maternity care, there is strong evidence to suggest that for hospital

53 Pregnancy was cited as the fifth most common reason for hospitalization in 1962.

54 Schnabel, 'Medizinisches aus Albert Schweitzers Urwaldspital'.

55 Müller, '50 Jahre Albert-Schweitzer-Spital'.

56 Schweitzer, Das Spital im Urwald: Aufnahmen von Anna Wildikann, 12-16. 
staff, and perhaps especially for its director, maternity services were not a main priority.

While Schweitzer always aimed to ensure that qualified surgeons performed surgical interventions, he did not specifically require an obstetrician, gynecologist, or midwife to carry out deliveries. This could be left to general physicians or nurses. From a medical point of view, this made sense: surgeons usually have the necessary skills to perform a cesarean, whereas an obstetrician is seldom equipped with sufficient surgical knowledge to perform other operations.

The Albert Schweitzer Hospital thus contrasts other hospitals in Africa. Most of those expanded their maternity services in the 1920s, and, by the outbreak of World War Two, had employed at least one midwife. In many parts of the continent, African women were trained for this purpose. ${ }^{57}$ In contrast, Schweitzer explained to Emmy Martin, in 1951 that 'as a midwife we need someone who at the same time does infirmary services' 58 As seen at various points in this book, Schweitzer expected flexibility from his staff, a characteristic that he considered more important than the holding of a formal biomedical diploma in an obstetric specialty. Nurses responsible for the maternity ward had to carry out a range of other duties. They worked in the pharmacy, cared for women who had recently undergone surgery, administered injections, and assisted the physicians during consultations and even during the anesthesia process. ${ }^{59}$ Most of these women had no special training in obstetrics; those who did also had to work outside of the maternity ward. ${ }^{60}$

57 Turrittin, 'Colonial Midwives and Modernizing Childbirth in French West Africa', 71; Bell, Frontiers of Medicine, 199; Summers, 'Intimate Colonialism', 804.

58 Schweitzer to Martin, 17 December 1951, AMs.

59 Martinelli-Stettler, 'Wie eine Insel', 122; Weber to Schweitzer, 13 November 1934, AMS; Lagendijk to Schweitzer, 14 January 1949, AMS; Lagendijk to Schweitzer, 14 September 1957, AMs.

6o Mathilde Kottmann arrived in July 1924 and became the second nurse, after Helene Schweitzer, to be employed at the hospital. As its secretary until Schweitzer's death, she would later hold a position that was crucial for the smooth running of the institution. She had some background in midwifery and/or the care of newborns. See: Munz and Munz, Albert Schweitzers Lambarene, Zeitzeugen berichten, 123; Woytt-Secretan, Albert Schweitzer baut Lambarene, 20-21. Another exception was Alice Schmidt who attended a midwifery school in 1936, before coming to Lambaréné after World War Two as a general nurse. See: Martin to Schweitzer, 14 December 1936, AMs. 
Like the nurses, the doctors responsible for maternity care were required to perform numerous other tasks. In addition to supervising the maternity ward, Dr. Anna Wildikann, for instance, treated ulcers, performed operations, assisted at other surgical interventions, and provided dental services. ${ }^{61}$ In the late 1950s, Dr. Greet van der Kreek was in charge of the maternity ward, but also had to look after some of the surgical patients. ${ }^{62}$ In 1957, she remarked that 'managing deliveries has gradually become so much work [...], that it is almost a task in itself', ${ }^{63}$ suggesting that caring for patients and new mothers had not been enough workload to fully occupy one nurse up to then. When South African midwife Olive du Preetz arrived in 1959, she was the first nurse to be given the space to focus entirely on maternity care, which included managing the nursery and looking after premature babies. ${ }^{64}$ Jo Boddingius, a Dutchwoman who had also obtained her midwifery diploma in South Africa and who would later marry Dr. Walter Munz, took up the post in 1962, after the numbers of deliveries at the hospital had increased drastically. Although a European nurse, 'who had learned in Lambaréné how to supervise deliveries', stood in for her on two nights per week and on every other Sunday, she felt overwhelmed by the amount of work she had to carry out. ${ }^{65}$

From the 1930s, African women were given the role of looking after the hospital's newborns and orphans at its 'pouponnière', a unit in which children of staff members and orphans were accommodated (see Illustration 19). In the memoir of her stay in Lambaréné from 1933 to 1935, the nurse Jeanette Siefert recalled that Bike, the gardener's wife, assisted in bathing, feeding, and changing the diapers of infants. Unlike European medical personnel in other colonies and many of her colleagues at the hospital, Siefert had full confidence in African women's abilities to babysit. Describing Bike, she wrote: 'Like all black women, she was loving and indulgent to the children; she was patient, let herself be tyrannized by them'. Siefert then quoted a letter she had received from Schweitzer in which he acknowledged Bike's contribution and promised her a

61 See, for example, her letters to Schweitzer dated 15 December 1935; 25 March 1936; and 15 August 1936; these are held at the AMs. Wildikann first served in Lambaréné from 1935 to 1937 and was on very good personal terms with Schweitzer. She would return to the hospital during World War Two.

62 Van der Kreek to Schweitzer, 27 October 1959, AMs. As the letter continues, van der Kreek discusses various surgical challenges with which she was confronted. Maternity services, on the other hand, are not mentioned again.

63 Van der Kreek to Schweitzer, 18 August 1957, AMs.

64 Schoenfeld, 'A Summer at Dr. Schweitzer's Hospital (Draft)', AMs, 16.

65 Munz-Boddingius, 'Meine Chance und Freude, Hebamme in Lambarene gewesen zu sein', $65^{-66 .}$ 


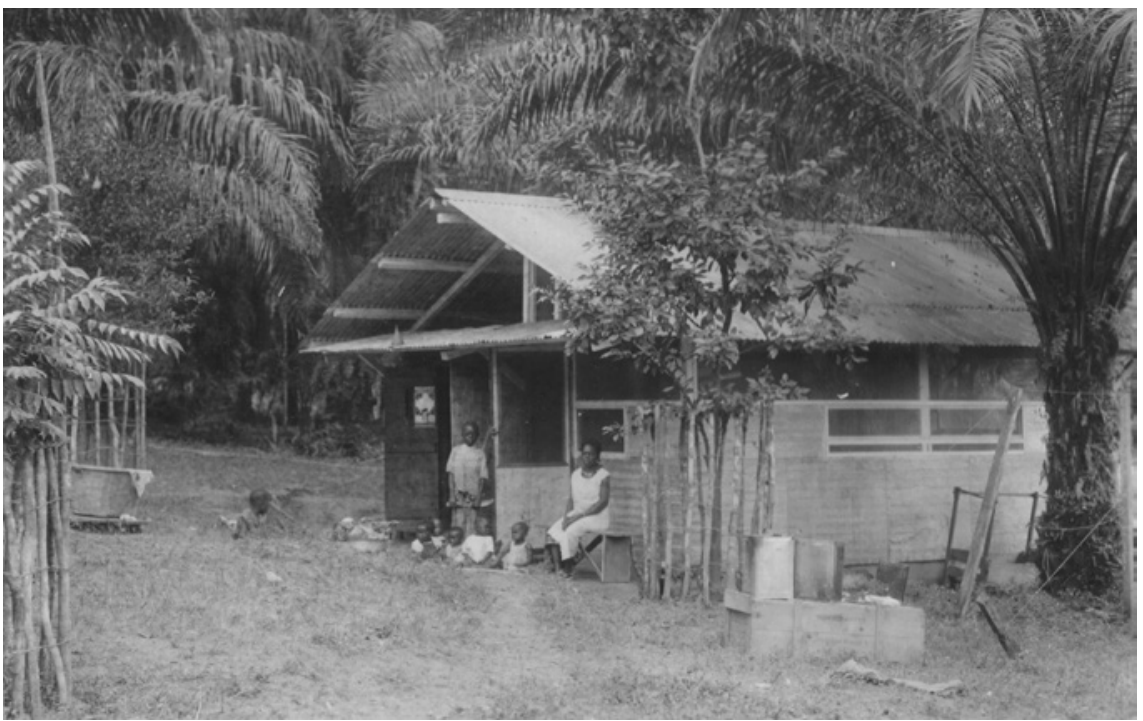

ILlustration 19 The 'Pouponnière', the hospital's day-care facility for children of staff and orphans, 1935

(C) ARCHIVES CENTRALES ALbERT SCHWEITZER GUNSBACH

'beautiful present'.66 This was rare praise, because later in the 1930s Schweitzer complained about the ignorance of African women in matters of childcare. By that stage, as he wrote, only N'Fagha, the widow of an auxiliary, 'fulfills her duties with great conscientiousness and with touching devotion she cares for the poor little beings entrusted to her'.67 Judging from this small set of evidence, African personnel in the maternity ward were given specialized roles earlier than their European colleagues.

By the early 196os, there were four African assistants in the maternity ward, all of whom were women. ${ }^{68}$ One of these was Daudette Azizet Mburu, whom I interviewed in 2015. She gave birth to seven children at the hospital from 1951 to 1963. After her last delivery, Schweitzer offered her the opportunity to stay on and work as an 'infirmière accoucheuse', a delivery nurse. ${ }^{69}$ Describing the tasks that African auxiliaries had to perform in the maternity ward, Mburu first recalled having to clean the unit. She also received the mothers-to-be and

66 Siefert, Meine Arbeitsjahre in Lambarene 1933-1935, 97.

67 Schweitzer, 'Briefe aus dem Lambarene Spital xx Mai 1937', 4.

68 Munz-Boddingius, 'Meine Chance und Freude, Hebamme in Lambarene gewesen zu sein', 65 .

69 Interview Daudette Azizet Mburu. 
cared for them until they were ready to deliver. When a woman went into labor, Mburu called for the nurse-in-chief. If a quick and unproblematic delivery followed, African auxiliaries could assist the mother without supervision of a European superior. ${ }^{70}$ They were also indispensable for translating the numerous languages spoken by patients. ${ }^{71}$ Given the general tendency not to mention Africans in most contemporary sources, including in the surgical protocols, it comes as no surprise that the role played by African auxiliaries was usually not noted in the birth protocols that were maintained in the ward. ${ }^{72}$

Clémentine Boucah's story, as told by her children Marie-Joséphine and Jacques, provides us with an example of how African assistants were recruited. ${ }^{73}$ She began serving at the Albert Schweitzer Hospital as an infirmière accoucheuse after the death of her husband in the mid-1950s, having been invited to do so by her uncle, who already worked at the hospital. The institution had required assistance in the pouponnière, which was under the supervision of Suzanne Awo, who had worked at the hospital since at least 1947 and was frequently referred to as Mama Suzanne in the sources and the interviews I conducted (see Illustration 20). ${ }^{74}$ Clémentine Boucah, who was assigned to assist her, was trained on the job. At that point, this involved assisting during deliveries, which were performed by Awo and the on-duty European nurse.

Other children of African employees recount similar stories. Albert Bouassa's father came to work at the hospital in the early 1930s, joining his brother, who was already employed there. Anne-Marie Padje-Poabalou, who started to work at the hospital in 1967 , was the daughter of the long-serving auxiliary Ambroise Nyama. ${ }^{75}$ Positive references and personal connections, especially kinship ties, were a great asset for those who sought employment at the Albert Schweitzer Hospital. This also applied for European personnel.

When a prospective employee showed an interest in serving at the hospital, Schweitzer or Emmy Martin would request information about the person from trusted sources. Formal biomedical qualifications were of secondary interest, as various examples from the maternity ward illustrate. Maria Lagendijk, who

\footnotetext{
$70 \quad$ Ibid.

71 Munz-Boddingius, 'Meine Chance und Freude, Hebamme in Lambarene gewesen zu sein', 66 .

72 The first African auxiliary mentioned in the birth protocols was Boyé Suzanne in September 1961. L - P - A4, AMs.

73 Interview Marie-Joséphine Ndiaye-Boucah; Interview Jacques Boucah.

74 Awo's grandson claims that she started to work at the hospital in 1935. Interview JacquesAdrien Rolagho. A 1962 'list of the longest-serving employees, proposed for a decoration' lists her year of arrival as 1947. She is the only woman on the list, in which she bears the title of 'aide-infirmière'. The list was found in a folder entitled 'affaires concernant le personnel indigene', within a box with the brief title 'divers', in the cellar of the AMs. Interview Albert Bouassa; Interview Anne-Marie Padje-Poabalou.
} 


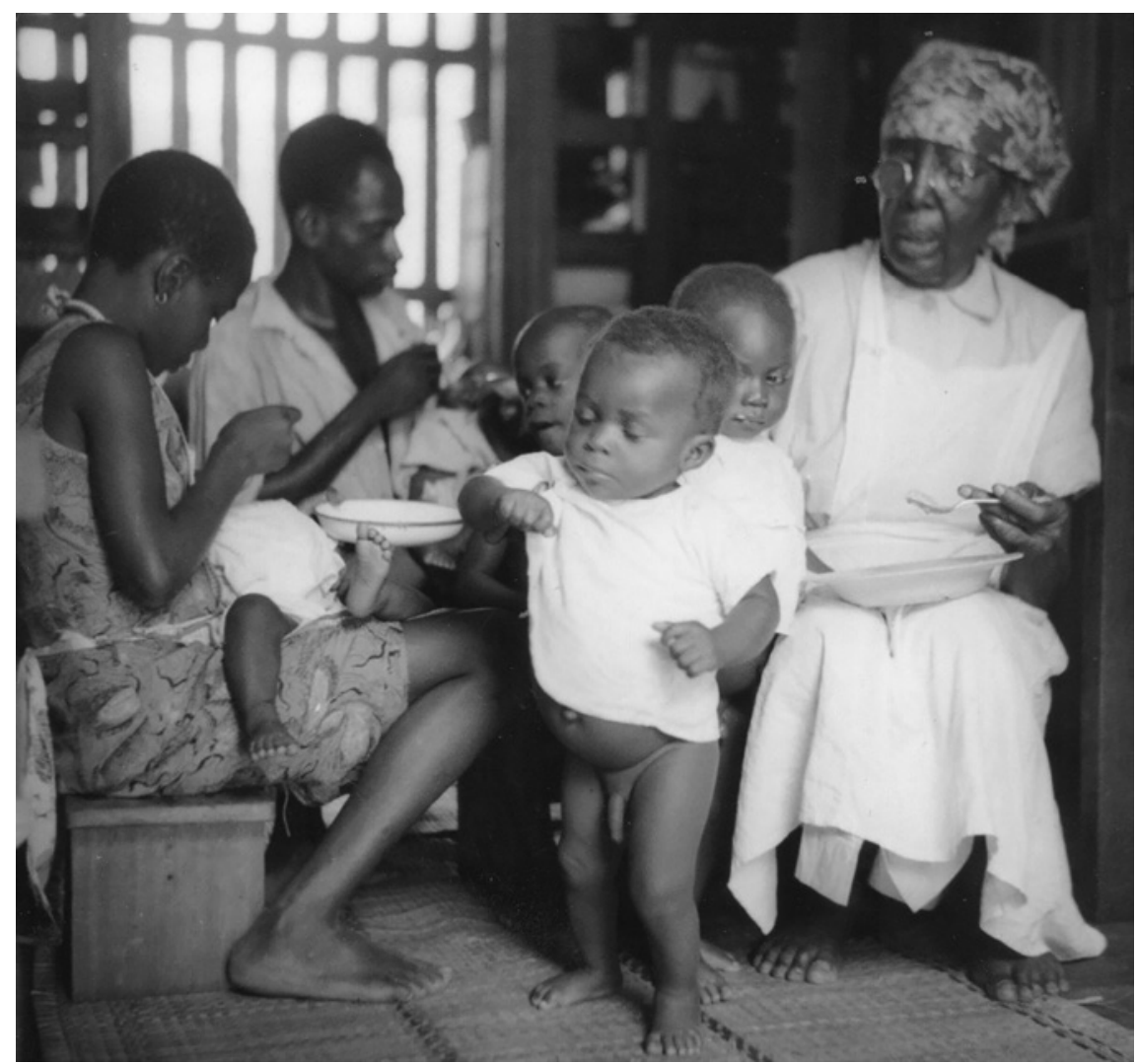

ILLUSTRATION 20 Suzanne Awo and unidentified nurses or parents feeding babies, mid-1950s

(C) ARCHIVES CENTRALES ALBERT SCHWEITZER GUNSBACH

would return to serve in Lambaréné on several occasions until after Schweitzer's death, had obtained a midwifery diploma in Britain and was able to 'independently lead deliveries', as Martin added in brackets in her letter presenting Lagendijk to Schweitzer in August 1938. However, this was not the main reason for employing her; Martin instead underlined that Lagendijk 'doesn't have to take care of anyone. Impression very kind and fine. [...] The medical report is good. [...] I made inquiries about her, they were good, too. Analysis very good. ${ }^{76}$ The final point refers to handwriting analysis, a test which Schweitzer routinely had done for each candidate by a specialist in Paris.

From this analysis, Schweitzer expected to gain insights into the applicant's personality, the favorable assessment of which represented a key precondition

76 Martin to Schweitzer, 11 August 1938, Ams. Like other prospective employees, Lagendijk was sent to two doctors - one in Alsace, one in Rotterdam - for medical examinations. 
for being hired. Schweitzer looked for characteristics that were consistent with the 'Lambaréné Spirit'. For example, the results for Devika Frankenbach were 'not brilliant' - he suspected that she was a 'housemaid' - but since she was described as 'willing to work' and 'reasonable' he made further enquiries. ${ }^{77} \mathrm{Af}-$ ter learning that Frankenbach was a nurse, Schweitzer ordered that she should be 'be instructed in all areas of medical operations so that she can be deployed anywhere. ${ }^{78}$ At the beginning of her stay in 1957 , Frankenbach was found to be 'too nervous' to distribute medication, ${ }^{79}$ but she ultimately found her place at the hospital, returning for a second stay in the early 196os, during which she worked in the maternity ward. ${ }^{80}$

More important than the findings of handwriting analyses were personal references. In 1939, a midwife from near Gunsbach with eighteen months of work experience expressed an interest in serving in Lambaréné. Martin rejoiced: 'Of course, it would be wonderful to have someone from here and even a midwife. ${ }^{81}$ After further inquiries, however, the candidate's superior gave a 'unfavorable report', leaving Martin to conclude that 'she has a bad character, so she's not an option for us.' ${ }^{82}$ The Swiss nurse Sonja Müller, who would serve two terms in the maternity ward in the 1950s, had worked as a nurse in Conakry, but had undergone no formal training as a midwife. ${ }^{83}$ Her personal references were so convincing that Schweitzer employed her in 1955 without waiting for the results of a handwriting analysis. ${ }^{84}$ By recruiting staff that he thought would adhere to the 'Lambaréné Spirit', Schweitzer ensured that they ignored, or at least quietly accepted, local delivery practices. This careful selection of personnel thus contributed to processes of unknowing and to the hospital's guiding vision of healthcare provision.

In order to understand Gabonese women's motivations for choosing hospital births and their experiences thereof, it is useful to compare the delivery

77 Schweitzer to Martin, 1 August 1956, AMs.

78 Schweitzer to Martin, 25 November 1956, AMs.

79 Van der Kreek to Schweitzer, 18 August 1957, AMs.

80 Stocker, 'Diary 1961-63', 3; Schoenfeld, 'A Summer at Dr. Schweitzer's Hospital (Draft)', AMs, 17. It remains unclear if Frankenbach attended some form of obstetrical training before returning to Gabon.

81 Martin to Schweitzer, 4 April 1939, AMs.

82 Martin to Schweitzer, 6 May 1939, AMs.

83 Schweitzer to Martin, 15 March 1955, AMs.

84 Schweitzer to Martin, 25 March 1955, AMS. 
process in a biomedical ward with that which typically occurred in the settlements of Gabon. A considerable number of ethnographies provide information on the latter; however, they often did not report in detail on the act of giving birth itself. Instead, they focused on aspects that were ignored or did not occur at the Albert Schweitzer Hospital, such as post-delivery rituals concerning the placenta or the umbilical cord. It is unclear whether it was the African informants, the mothers, or the ethnographers themselves who were more interested in discussing these customs than the actual delivery process.

A period of seclusion after childbirth, during which the mother was not allowed to leave the hut in which she had given birth, was customary among the Fang of Gabon. ${ }^{85}$ At the Albert Schweitzer Hospital, mothers were also kept in a maternity ward for some time, where they were looked after, hidden from the male gaze. However, the degree of privacy and silence afforded to the mother was quite different in these two settings. Ethnographers from different periods generally agree that the delivery of the baby and the postnatal seclusion happened in the village of the new mother's own mother ${ }^{86}$ Reasons for this move were not given, but can be understood in two ways in relation to hospital births. The more straightforward interpretation is that this habit hindered hospital births. However, it is also plausible that this passage was not about soil or place, but leaving the environment of the father's family and passing through a symbolic voyage into the mother's family and an all-female environment. Since her mother and other female relatives could accompany a pregnant woman to Schweitzer's hospital, its maternity ward can thus be interpreted as representing a setting as suitable for childbirth as the maternal village.

Some oral testimonies assert that a woman would come to the hospital in the eighth month of her pregnancy. ${ }^{87}$ In contrast, Azizet Mburu reports that

85 Ethnographers have not agreed on how long this period normally lasted. In the early twentieth century, Tessmann described how mothers would stay in the hut in which the birth had occurred for eight to ten days. Another month to two months would pass before they would be allowed to take up their regular duties once again. See: Tessmann, Die Pangwe, 2:276. Fernandez, who conducted his fieldwork in the late 1950s, wrote that mothers would remain in the hut together with the baby for up to one month. See: Fernandez, Bwiti, 115 .

86 Tessmann, Die Pangwe, 2:274-75; Alexandre and Binet, Le groupe dit Pahouin, 91; Fernandez, Bwiti, 115. Henri Trilles, in contrast, reported that the mother-in-law played the key role in the birth ritual, which took place in the husband's home village and saw the participation of all local women. See: Trilles, 'Les rites de la naissance chez les Fang', 405. Other parts of Trilles' work, notably his theories on the origins of the Fang, have been rejected by the majority of anthropologists and historians. See: Cinnamon, 'Missionary Expertise, Social Science, and the Uses of Ethnographic Knowledge in Colonial Gabon', 430.

87 Emane, Docteur Schweitzer: une icône africaine, 124. Some of my interviewees recalled the same. See: Group Interview Port-Gentil; Interview Marie-Joséphine Ndiaye-Boucah. 
there was no firm rule in this regard: some women arrived shortly before delivery; others had already been coming for regular consultations for months. ${ }^{88}$ According to Jo Munz, the ideal scenario was for a woman to come for prenatal consultations as soon as she suspected a pregnancy. She would then be asked to return to the hospital two weeks before the anticipated date of birth. ${ }^{89} \mathrm{In}$ 1961, the nurse Marianne Stocker recorded in her diary that a pregnant woman would come to the hospital 'a few weeks before the delivery' and stay there until her baby weighed more than three kilograms and its umbilicus was dry. ${ }^{90}$ Jo Munz reported that the latter typically occurred three weeks after the birth. ${ }^{91}$ According to Azizet Mburu, mothers usually left the hospital after eight days, if the doctor who had visited them daily permitted them to do so. ${ }^{92}$ These differences in medical guidelines reflect the piecemeal nature in which the hospital was run. They also underline the agency of mothers, an agency similarly observed among surgical patients in the previous chapter.

To gain more insight into how childbirth occurred at the hospital, an entry from Stocker's diary for 22 April 1961 can be compared to other accounts from the same period. Stocker usually worked as a pediatric nurse and was not required to perform midwifery duties, but on this particular night her assistance was requested by the on-duty nurse in the maternity ward.

A birth under petroleum light. Everything was a bit more primitive but not unclean. Mother and grandmother held the head and hands of the woman giving birth. Other family members waited in front of the building. From time to time we hear them sigh and sometimes laugh. A strong, rosy girl was born. She screamed and kicked her legs. 'A girl, you are rich', said the black aide. 'Thank you thank you', laughed the grandmother and pranced around in the room, humming a monotonous melody. Evangeline bathes the child, dresses her and puts her in a liana basket. [...] Mother and child remain in the delivery room for two hours. Then the woman who has recently given birth walks into her case on foot. The grandmother follows, carrying the little basket with the child on her head. ${ }^{93}$

In this passage, instead of discussing the baby's delivery, Stocker focuses on the presence and behavior of family members and on the postnatal mobility of the

\footnotetext{
88 Interview Daudette Azizet Mburu.

89 Interview Munz and Munz.

90 Stocker, 'Diary 1961-63', 7 .

91 Interview Munz and Munz.

92 Interview Daudette Azizet Mburu.

93 Stocker, 'Diary 1961-63', 6-7.
} 
mother. She does not specify if the birth occurred with the mother in a lying or sitting position. According to both Jo Munz and Azizet Mburu, lying was the standard birth position used at the hospital. ${ }^{94}$

Azizet Mburu, however, disagrees with Stocker on whether relatives could be present during the birth, recalling that they were made to wait outside the delivery room. Schoenfeld reported that the mother of a woman in labor would usually wait at her daughter's bedside while five to six other family members waited outside. ${ }^{95} \mathrm{He}$ did not mention any dancing or singing, a vivid memory of the dentist Frederick Franck, who had his dentistry next doors. ${ }^{96}$

Like Stocker, the visiting pediatrician Hermann Mai was struck by how quickly new mothers regained their mobility. In his diary, he noted that 'on the day of her child's birth I saw the mother carrying buckets of water on her head. She got up after the removal of the placenta and walked away as one gets up from eating (or the opposite!). ${ }^{97}$ On this point, Schoenfeld disagreed slightly, reporting that a new mother typically 'walked to a wooden stretcher and was carried to the cottage. She was usually out of bed the following morning. ${ }^{98}$

These diverse reports from the same time period illustrate that very few strict rules were enforced during childbirth, in complete contrast to the processes prior to and during a surgical intervention; less control was deemed to be necessary during the delivery process (see Illustrations 21 and 22). Still, women were made to give birth in a room in the Grande Pharmacie, some distance away from their sleeping quarters. Schweitzer wanted medical procedures to take place at a central location, where he could easily oversee and control them. Recurring reports of babies being born elsewhere on the hospital grounds suggest that this was not as easy to ensure in the delivery room as it was in the surgical ward. Protocols list deliveries taking place on pirogues, in the sleeping quarters for pregnant women, or on a sandbank in the river in front of the hospital. ${ }^{99}$

European medical personnel at the Albert Schweitzer Hospital were remarkably ignorant of local birth practices and the significance that local residents attached to these. The nurse Elisabeth Anderegg, for example, recalled a

\footnotetext{
94 Munz-Boddingius, 'Meine Chance und Freude, Hebamme in Lambarene gewesen zu sein', 68; Interview Daudette Azizet Mburu.

95 Schoenfeld, 'A Summer at Dr. Schweitzer's Hospital (Draft)', AMs, 17.

96 Franck, Days with Albert Schweitzer, 100.

97 Hermann Mai's diaries are held at the AMs. This entry is from 1958.

98 Schoenfeld, 'A Summer at Dr. Schweitzer's Hospital (Draft)', AMs, 18.

$99 \mathrm{~L}-\mathrm{P}-\mathrm{A} 2-5$, AMs. For the pirogues: April 1959, October 1959, April 1962, January 1964; for the sleeping quarters: January 1959, March 1962, August 1963; for the sandbank: September 1963 .
} 


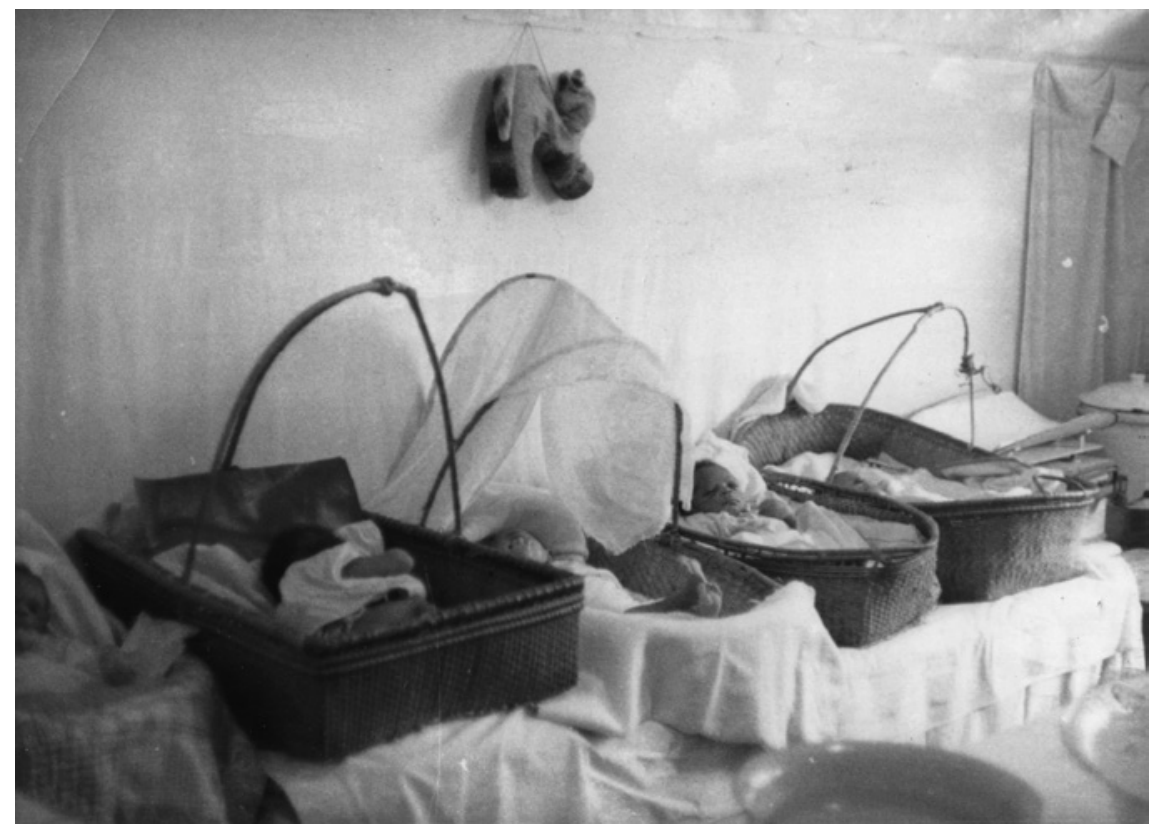

ILLUSTRATION 21 Accommodation for babies, undated

(C) ARChIVES CENTRALES ALBERT SCHWEITZER GUNSBACH

woman who arrived at the hospital with a piece of rock attached on a liana to the umbilical cord with which to extract the placenta. Anderegg commented this episode as follows: 'we couldn't understand it. The way they treat ... in these villages'.100 In various accounts, staff members proclaimed the outlandishness of Gabonese practices from their biomedical point of view. These descriptions are important because they prove that staff were confronted with different childbirth practices and that knowledge about these circulated among them. They illustrate how ignorance functioned on many dimensions at the hospital. Narratives of childbirth blur the question of who is ignorant of what, as the following examples demonstrate.

In 1949, Joy and Arnold reported a number of pregnant women who had come 'to get hospital care before and after childbirth but, fearing that a male doctor may help in the delivery, steal off into the bush and then carry the crying infant into the Hospital. ${ }^{101}$ Yet, similar occurrences were recorded in the birth protocols even when a woman was in charge of the maternity ward. This

100 Interview Elisabeth Anderegg.

101 Joy, Arnold, and Schweitzer, The Africa of Albert Schweitzer, 132. 


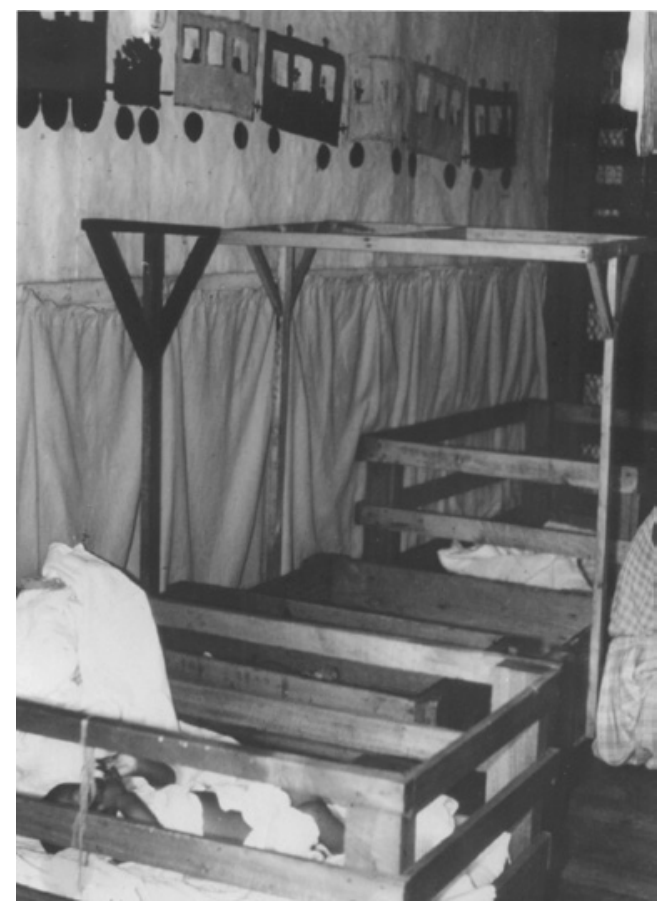

ILLUSTRATION 22 Another accommodation for babies, also undated

(C) ARChives CENTRALES ALbERT SCHWEITZER GUNSBACH

suggests that these mothers may have been motivated by different reasons, which are difficult to discern from our sources.

Another example is from a letter written to Schweitzer by Dr. Wildikann in March 1936. Schweitzer did not reproduce the story in print, even though he enjoyed publishing such anecdotes of exotic and supposedly ignorant practices of locals. Wildikann reported the following:

By the way, I recently experienced a delightful joke that I have to tell you in my 'obstetric practice'. A young Pahouin brings his pregnant wife (about 6-7 months) for examination. My stethoscope makes a big impression on both of them. After listening to the children's sounds, the man asks me: 'does my son already speak?' In my high spirits, I answer: 'yes, yes he starts to do so already', whereupon the good little negro shines so that his beautiful teeth become visible up to his ears and he asks me: 'What did he tell you?'102

102 Wildikann to Schweitzer, 25 March 1936, AMs. 
Wildikann did not provide any further comment on this episode. As a result, we cannot tell if she thought that the husband was joking or ignorant. In any case, she did not simply dismiss the man's words as uninformed by correcting him or trying to impose her judgment. Instead, Wildikann responded in a humorous way, a reaction that at the same time acknowledged the man's point of view and denied its validity, which was one way to unknow local practices and perspectives.

In one 'African Story', a collection of which Schweitzer published in a booklet in 1939, he told of one of many women who believed that she was living under a 'taboo' that would kill her if her firstborn was a boy. When her first baby was delivered in her mother's village, it cried like a boy. After discovering that it was actually a girl, the new mother insisted that it had changed sex after delivery. A few days later, she was brought to the hospital 'severely emaciated' and could not be saved. Schweitzer believed that her illness was [...] of entirely psychological origin. ${ }^{103}$ Besides suggesting that locals perceived the hospital as a last resort in the case of certain afflictions, this example illustrates the inability of hospital staff to grasp issues that lay beyond the biomedical sphere. ${ }^{104}$ Schweitzer did not deny that 'taboos' had real effects, but he referred to the woman's psyche and thus provided a rational interpretation. It is an illustration of how, when confronted with practices and attitudes that they considered primitive, staff unknew those by explaining them from a biomedical perspective or by making jokes. Instead of actively attempting to change local realities and practices, they were encouraged to find pragmatic solutions within the hospital.

Norwegian pediatrician Louise Jilek-Aall, who worked at the hospital in 1961, provides an account which suggests that Schweitzer was reasonably knowledgeable about local ideas on childbirth. ${ }^{105}$ On one occasion, she accompanied the hospital's mechanic Siegfried Neukirch on a journey in a truck to collect plantains and other food. On their way, they were called into a hut, where an old woman lay seriously ill. To her own surprise, Jilek-Aall found the woman to be pregnant. At first, her husband reacted in a slightly offended manner: "Why do you make a joke?" he asked, "we are prepared for bad news"'. The doctor could not convince them of her diagnosis, but they readily agreed to visit the hospital to have Schweitzer solve the mystery. On confirming JilekAall's verdict, Schweitzer commented to her pessimistically:

103 Schweitzer, Afrikanische Geschichten, 54.

104 See Chapter 5 for a discussion of this issue.

105 Jilek-Aall, Working with Dr. Schweitzer, 97-101. 
What will the future hold for this child? To the African it is an unnatural event to bear a child at this mother's advanced age. Witchcraft will be suspected by the neighbors. Even the parents will be afraid of the child and probably let it succumb before long.

Schweitzer then confirmed the diagnosis to the disbelieving couple, adding:

I know it sounds impossible to you and you would rather not have another child at your age, but to us, this will be a special baby. We would like to make it a child of the hospital. Leave the child with us - if it is a boy, I shall give it my name; if a girl, we shall name it after la doctoresse. You need not tell anyone just stay at the hospital and look after your wife until she is well. When the child is born, we will keep it in our nursery. Should you wish to return at a later date to see your child, you will know which one is yours by its name. ${ }^{106}$

They were placed in quarters all by themselves, and the wife's condition improved. After a trouble-free delivery, 'the couple lingered on in the hospital much longer than we thought necessary. But we never saw them visit the nursery or display any interest in their child'.

A number of more general descriptions of non-hospital deliveries in Gabon emerge from the early $1960 s$. According to Jo Munz, a woman in labor would be watched over by a local birth attendant, usually an elderly woman. The former would lie on a banana leaf with her legs on the attendant's shoulders, her mother or another relative sitting behind her and holding her. According to Munz, the only course of action that a birth attendant could take if a delivery did not progress smoothly was to encourage the woman to push more forcefully; if unsuccessful, a failure of the cervix to open would often lead to the death of the mother or child. ${ }^{107}$ When Dr. Müller explained local birth practices to a specialist medical readership, he also mentioned the older women who acted as birth attendants; however, he disagreed with Munz on the preferred position for delivery and claimed that 'as soon as the woman feels the urge to push, she goes into a squatting position and often only a few labor pains are enough to expel the infant'. Müller concluded that 'the majority of the deliveries runs smoothly', but shared Munz's general concern that 'a prolonged course, however, can lead to numerous complications: pushing when the cervix is often incompletely opened exhausts the woman and damages the

106 Ibid., 100.

107 Interview Munz and Munz. 
child' ${ }^{108}$ Staff's preoccupation with the cervix reveals their biomedical training and its focus on anatomy. In their view, African ignorance in obstetrics was palpable and could prove to have fatal consequences in complicated cases.

According to some ethnographies, the sitting-on-banana-leaves birth position was customary throughout the study period, ${ }^{109}$ but the birth position was not specified by the majority of the authors. They showed particular interest in the burying of the umbilical cord, ${ }^{110}$ the placenta, ${ }^{111}$ or both, ${ }^{112}$ which they claimed to be of crucial importance for the new mother's family members. The exact details of this procedure, as well as the specific person responsible for its execution, remain vague. James Fernandez interprets the afterbirth as representing a kind of 'second person' or 'twin of the newborn who must die and be carefully buried lest animals or witches discover and devour it and bring harm to the newborn'.113 Some colonial officials also recognized the deep significance of the practice. In 1934, for example, placentas were returned to the families of women who had given birth at the newly opened maternity ward in the Kong Hospital in Libreville. ${ }^{114}$ In view of the great symbolic meaning attached to the afterbirth among the Fang, it is striking that this custom goes almost unmentioned in our sources relating to Schweitzer's hospital. The one exception was visitor Schoenfeld, who wrote that 'the grandmother disposed of the placenta (usually in the river)', ${ }^{115}$ suggesting that it was a practice that frequently occurred.

Clear from the ethnographic writing is that childbirth was an exclusively feminine domain in Fang society. Men were not allowed in the same hut during the delivery. The ethnographic authors emphasized that the newborn baby's grandmother from the maternal side was normally present. According to Fernand Grébert, serving for the Paris Evangelical Mission in Gabon from 1913 to 1932, female birth attendants were fully competent and had long been powerful actors in Fang society. ${ }^{116}$ Ethnographers who were not trained in medicine usually

108 Müller, '5o Jahre Albert-Schweitzer-Spital', 25-26.

109 Trilles, 'Les rites de la naissance chez les Fang', 407-9; Alexandre and Binet, Le groupe dit Pahouin, 91.

110 Trilles, 'Les rites de la naissance chez les Fang', 410; Alexandre and Binet, Le groupe dit Pahouin, 91.

111 Tessmann, Die Pangwe, 2:276; Gaulene, 'Coutumes des races gabonaises'. In: 'Rapport Annuel du Service de Santé de la Colonie du Gabon 1932', ZK 005-127. SHD.

112 Fernandez, Bwiti, 447.

113 Ibid.

114 'Rapport Annuel du Service de Santé de la Colonie du Gabon 1934', ZK 005-127, SHD.

115 Schoenfeld, 'A Summer at Dr. Schweitzer's Hospital (Draft)', AMs, 18.

116 Grébert, $A u$ Gabon, 132. Tessmann is the only ethnographer who made no mention of birth attendants. See: Tessmann, Die Pangwe, 2:275. 
did not judge their obstetrical ability, with the exception of Alexandre and Binet. According to them, 'the technique of midwives (is) extremely uneven: while some know how to perform artificial deliveries and even how to turn feti around, most of them are limited to massages and magical practices'.17

From the Albert Schweitzer Hospital, Dr. Wildikann claimed that it was the desire of African mothers-in-waiting to be attended to by a woman. She had 'the strong conviction that women have themselves examined with good confidence and less timidity by a female doctor."118 Schweitzer cited the same reason when he demanded the immigration permit for Wildikann during World War Two, insisting that 'indigenous women come more easily to a lady than a man'.119 The argument that local women would only accept the care of female medical personnel, so overt elsewhere, ${ }^{120}$ is less conspicuous in our case, but its maternity ward remained a largely female domain throughout the study period. ${ }^{121}$

Augustin Emane argues that giving birth at the Albert Schweitzer Hospital was considered a privilege by his informants, not only because Schweitzer himself provided protection from malign forces and submitted the birth certificate, but also because the baby was 'was surrounded by white women (known to be more competent and reliable) who will take care of him as well as dress him'.122 According to this claim, it was not only European staff members at the hospital who considered Africans ignorant in matters of childbirth, but also African women themselves. This assertion, while difficult to evaluate, supports the argument that biomedicine diffused successfully in Gabon and changed perceptions of childbirth in the territory. As key to achieving the latter, Emane cites the free distribution of clothes for newborns, a practice that was also fondly recalled by my interviewees. ${ }^{123}$ They

117 Alexandre and Binet, Le groupe dit Pahouin, 92. Italics mine.

118 Wildikann to Schweitzer, 18 June 1936, Ams.

119 He also underlined Wildikann's skills in dental care, a service from which many Europeans in the territory benefited; Schweitzer to Mandel, 26 January 1940, AMs.

120 Ndao, 'Colonisation et politique de santé maternelle et infantile au Sénégal'; Summers, 'Intimate Colonialism', 802f.

121 When the number of deliveries increased and the percentage of female doctors at the hospital decreased after 1960, female midwives continued to be hired for the purpose of routinely attending deliveries, as mentioned above. Throughout the study period, male doctors were occasionally present to perform episiotomies or sutures for perineal ruptures, as the protocols indicate.

122 Emane, Docteur Schweitzer: une icône africaine, 124. A more detailed discussion on the Albert Schweitzer Hospital as a place of safety will be provided in Chapter 5 .

123 Group Interview Port-Gentil. This was also considered important by European personnel. See: Munz-Boddingius, 'Meine Chance und Freude, Hebamme in Lambarene gewesen zu sein', 68; Stocker, 'Diary 1961-63', 13 . 
also highlighted how valuable it was for mothers and babies to receive food. ${ }^{124}$ These factors must not be underestimated when answering the question of why women chose to deliver their babies at Schweitzer's hospital. In other parts of the continent, including at the Berceau Gabonais in Libreville, the distribution of extra-medical items such as clothes or soap was seen as key to luring pregnant women to hospitals. ${ }^{125}$

Schweitzer and his staff ignored colonial discourses on depopulation and domesticity, but also rarely reflected on what would motivate a Gabonese woman to choose to deliver her baby at a hospital or in her community. When staff members discussed maternity care, this was usually in connection with complicated cases. This suggests that they conceived of obstetrics as a purely medical service, one of many offered at the hospital. While abnormal cases were considered worthy of reporting, general developments, overall numbers of deliveries, or simple updates were rarely provided. The protocols, on the other hand, reveal that the majority of deliveries occurred without problems. Usually, between 80 and 85 percent of births per year were categorized as 'normal', as Table 2 illustrates. Staff had a broad understanding of what constituted 'normal' (see Illustration 23). This could include stillbirths, breech presentations, perineal ruptures or episiotomies, deliveries in the hospital's living quarters or on the pirogues, and deliveries with the help of labor-inducing medication or by vacuum extractor. Categorizations varied over time and depended on the nurse; the classification in Table 2 thus cannot be provided with full certainty. Furthermore, as protocols for most years are missing, the available information is extremely fragmentary.

Technological artifacts were of some importance in obstetric practices at the Albert Schweitzer Hospital. Forceps had been in use since at least the early $1930 s,{ }^{126}$ but by the early 1960 s, staff made every effort to avoid using these. Jo Munz did so by turning the fetus over before the thirty-sixth week, a practice prohibited in Europe but that she had learned in Johannesburg as a way of preventing not only deliveries by forceps, but also cesareans and breech presentations. During her time at the hospital, a vacuum extractor was introduced, which quickly established itself as a key technology for easing deliveries.

124 Interview Marie-Joséphine Ndiaye-Boucah; Interview Daudette Azizet Mburu.

125 Headrick, Colonialism, Health and Illness in French Equatorial Africa, 271.

126 Bonnema to Schweitzer, 18 December 1932, AMs. 
TABLE 2 Problematic deliveries

\begin{tabular}{|c|c|c|c|c|c|c|}
\hline Year & $\begin{array}{l}\text { Total } \\
\text { number of } \\
\text { deliveries }\end{array}$ & $\begin{array}{l}\text { Not } \\
\text { 'normal' } \\
\text { deliveries }\end{array}$ & $\begin{array}{l}\text { By } \\
\text { cesarean }\end{array}$ & By forceps & $\begin{array}{l}\text { By vacuum } \\
\text { extractor }\end{array}$ & $\begin{array}{l}\text { Premature Other } \\
\text { deliveries }^{\mathbf{a}} \text { complications }^{\mathrm{b}}\end{array}$ \\
\hline
\end{tabular}

(\%)

\begin{tabular}{lccccccc}
\hline 1938 & 82 & 14.6 & 2 & 2 & 0 & 0 & 8 \\
1939 & 57 & 3.5 & 0 & 0 & 0 & 1 & 1 \\
1940 & 55 & 16.4 & 0 & 0 & 0 & 3 & 6 \\
1941 & 43 & 9.3 & 0 & 0 & 0 & 1 & 3 \\
1953 & 70 & 24.3 & 5 & 7 & 0 & 3 & 2 \\
1954 & 74 & 18.9 & 4 & 4 & 0 & 1 & 5 \\
1959 & 176 & 18.8 & 18 & 6 & 0 & 4 & 5 \\
1960 & 195 & 15.9 & 21 & 0 & 0 & 3 & 7 \\
1961 & 320 & 13.8 & 23 & 2 & 0 & 6 & 13 \\
1962 & 357 & 14.0 & 15 & 2 & 7 & 13 & 13 \\
1963 & 350 & 20.6 & 11 & 1 & 45 & 7 & 8 \\
1964 & 334 & 19.2 & 24 & 0 & 25 & 6 & 9 \\
\hline
\end{tabular}

a Premature deliveries were sometimes considered 'normal'. I have listed all premature deliveries referred to in the protocols in this column, even when these were categorized as normal.

b This includes breech presentations, which were sometimes also categorized as normal', as well as other rare or unspecified complications.

Dr. Rolf Müller and Jo Munz tested it at the hospital on a few occasions as a potential replacement for forceps, after which Schweitzer was satisfied that it had demonstrated its superiority and lent his approval to its further use. ${ }^{127}$ According to the birth protocols, it was used when the baby's heartbeat was irregular or when the mother had pushed for more than thirty minutes without result. ${ }^{128}$

The focus on irregular birth cases is especially noticeable in the sources from the 1930 s onwards, when the new maternity ward was open and Schweitzer spent a considerable amount of time in Europe. In all her letters from 1936, Dr. Wildikann, who was at the time in charge of the maternity ward, reported irregular births to Schweitzer, but never discussed the general state of the

127 Interview Munz and Munz.

128 See, for example, the entries of April and July 1964. 


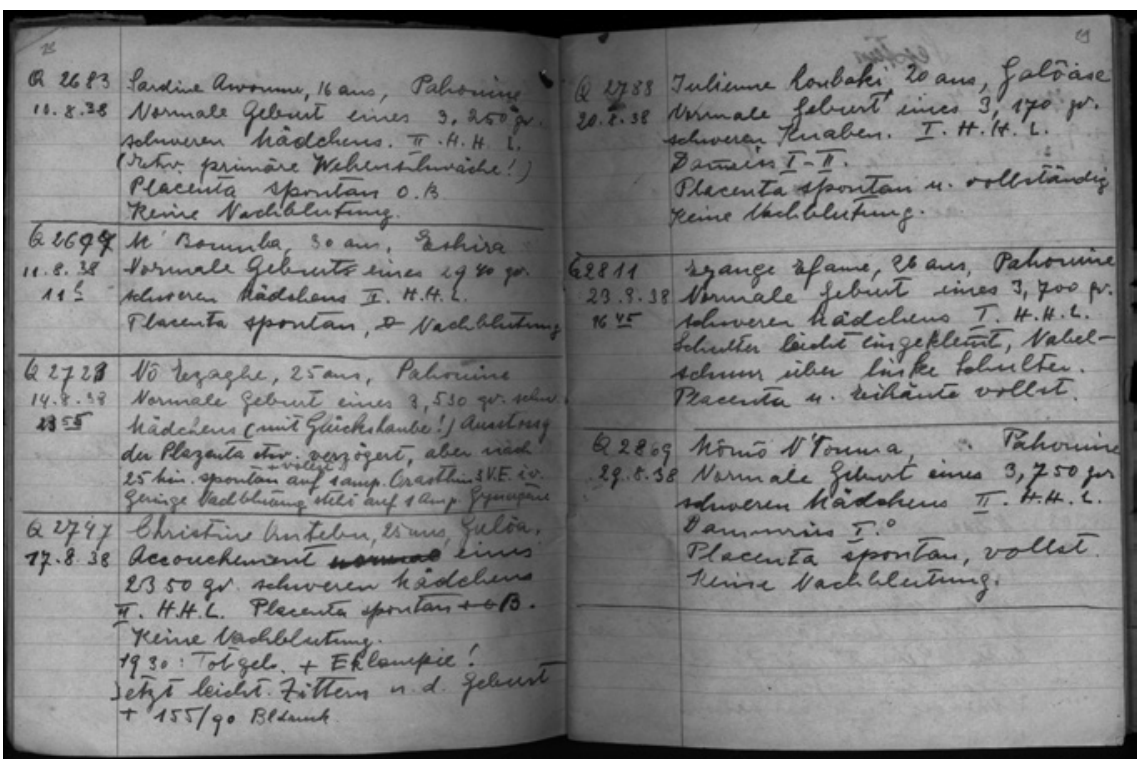

ILLUSTRATION 23 Delivery protocols of August and September 1938. All seven births were 'normal', despite a case of very tedious primary labor, a girl born with a caul, two perineal ruptures, and a girl born with the umbilical cord over her shoulder

(C) ARCHIVES CENTRALES ALBERT SCHWEITZER GUNSBACH

ward. ${ }^{129}$ Some irregular cases were stillbirths, explained with reference to the young age of the mothers and their narrow pelvises, a recurring concern to which I will return below. ${ }^{130}$ Other cases that Wildikann reported were those that she considered strange. For example, a pregnant woman had shown mild symptoms of smallpox one evening, upon which she was isolated. 'At the early consultation the next morning I found the woman in hard labor, the baby's head already visible', Wildikann wrote, continuning that 'as soon as I turned around to gather the most necessary things for delivery, the child was already there.'131 In another instance, she considered the limits of their diagnostic possibilities. When the uterus of a dysentery patient became swollen, the doctors suspected a tumor. One day, 'the woman felt a still desire' and went into the bushes near the river, where she delivered 'a tiny child of seven months'.132

129 The same is true for her aide, the Swiss nurse Emmy Röthlisberger, who provided considerably less detail.

130 Wildikann to Schweitzer, 15 August 1936, Ams.

131 Wildikann to Schweitzer, 8 April 1936, AMS.

132 Ibid. 
Such accounts contain a considerable degree of sensationalism, which is also a feature of Schweitzer's published writings. However, he preferred to print reports on huge cases of elephantiasis or on injuries suffered in animal attacks than on irregular deliveries. Presumably, he did not want to shock his supporters with stories of the deaths of innocent infants, but this publication strategy also reflects the marginal status of maternity care at the hospital. On another level, these accounts illustrate the agency of patients, as well as the limits of European doctors' knowledge and abilities.

Besides deliveries that were considered exotic or strange, medical personnel also deemed complicated ones worthy of reporting. A number of practices to extract babies were intrusive and potentially disturbing, as illustrated in a letter written in December 1934 by Dr. Ladislav Goldschmid, Wildikann's predecessor in the maternity ward. ${ }^{133} \mathrm{~A}$ woman was brought to the hospital after she had been in labor for four days - '(supposedly!)', as Goldschmid remarked. He diagnosed a second-grade pelvis constriction and dismissed the option of performing a cesarean, because 'the woman was too dirty'.134 Instead, he considered 'turning to the foot, high forceps, pulvotomy (sic) with Gigli saw, or craniotomy'. He chose to observe her condition for some time before making a decision, which he would base primarily on the 'further state of the woman', adding that 'of course I would also like to save the infant life.' ${ }^{135}$ In the letters that followed, Goldschmid did not clarify which option he had chosen, but similar cases can be traced in other sources from throughout the study period.

The most invasive and disturbing practice was the skull perforation, also known as craniotomy. The practice was still being performed as late as 1953 and 1954, even if rarely.136 A well-documented case occurred in 1936, when a pregnant woman arrived with seizures that the doctors identified as severe eclampsia. Dr. Wildikann wrote to Schweitzer that they carried out the perforation only 'after everything else had failed'. Dr. Heinz Barasch had to perform the procedure, 'because I lacked courage to do so'. Without further comment, she added that 'until now, the woman recovers fairly well'. ${ }^{137}$ In his report, Barasch claimed that the unborn child had already been dead, a fact to which Wildikann did not mention at all. He underlined that it had been too late to perform a cesarean, ultimately justifying this serious intrusion with the need

\footnotetext{
133 Goldschmid to Schweitzer, 26 December 1934, AMs.

134 It is difficult to discern what Goldschmid meant to say with this statement, but it illustrates his concern about asepsis.

135 Goldschmid to Schweitzer, 26 December 1934, AMs.

136 Protocols reveal one case in each of these years, as well as one in 1938. See: $\mathrm{L}-\mathrm{P}-\mathrm{Al}, \mathrm{L}-\mathrm{P}-$ A3 Ams.

137 Wildikann to Schweitzer, 18 June 1936, AMs.
} 
to end the birth process in order to save the mother's life. In a similar but slightly more optimistic manner to Wildikann, Barasch ended his account by assuring Schweitzer that 'the woman is well. ${ }^{138}$ In the Belgian Congo, medical personnel frequently employed craniotomy crotchets because Africans were said to believe that a cesarean would kill the mother. It was thus feared that attempting to perform one would damage the reputation of a hospital. ${ }^{139}$ Gabonese were also reluctant to undergo cesareans, as we will see below, but craniotomies did not occur frequently enough at the Albert Schweitzer Hospital to argue that they served as a substitute for the former.

Like elsewhere in Africa, cesareans were rare at the Albert Schweitzer Hospital during the interwar period, as indicated in Table 2; from 1925 to 1941, only three instances were reported. ${ }^{140}$ Indeed, this intervention was rarely performed anywhere in AEF. For 1935, for example, AEF records list only 3 cesareans in a total of 1,031 deliveries. In 1944, colonial authorities recorded 19 cesareans in a total of almost 7,500 births recorded in maternity wards throughout $A E F{ }^{141}$ This is somewhat surprising, since the procedure was performed frequently in predominantly Catholic metropolitan France, where medical tradition prioritized the life and baptism of the child. In Britain, on the other hand, priority was given to protecting the life of the mother and thus Cesareans were executed less frequently. ${ }^{142}$

There was no clearly stated policy on cesareans at the Albert Schweitzer Hospital. It was not specified if, in the case of severe complications, safeguarding the life of the mother or that of the child should be prioritized. Despite its staff members' diverse backgrounds and training - they were educated in a number of different countries and were of Protestant, Catholic, or Jewish faith - they tended to act first to save the mother. In December 1934, Dr. Goldschmid reported to Schweitzer what might have been the hospital's first cesarean, although his sober tone does not suggest a premiere had taken place. A woman who had been in labor in her village for two days was brought to the hospital. Goldschmid decided in favor of a cesarean, because 'otherwise I had to sacrifice the life of the child'. A 'fearful' period followed, during which the doctors suspected that the mother had caught a puerperal infection. Goldschmid blamed

\footnotetext{
138 Barasch to Schweitzer, 3 June 1936, AMs.

139 Hunt, A Colonial Lexicon, 223, 229, 235.

140 For the years prior to 1938, when the birth protocols become available, the annual 'Statistiques de l'Hôpital' only recorded one cesarean, which was performed in 1934. See: L - A S2, AMs.

141 See the annual reports of the Service de Santé for AEF, ZK oo5-121 (1933-36), ZK 005-160 (1939-44), SHD.

142 Moscucci, The Science of Woman, 141-43.
} 
African ignorance for the possibility of this affliction to occur in this case. 'Only God knows what they had done to the woman in the village', he wrote. After two days, however, he was happy to report that 'now the mother is in an excellent condition.' 143

Later in the decade, Wildikann and other staff members occasionally referred to the possibility of performing a cesarean. Yet, they never conducted one, in part because patients resisted. In 1936, the nurse Emmy Röthlisberger described a potentially complicated delivery, for which the husband accompanied his wife to the hospital. 'When we suggested to the husband to perform a cesarean, he left with her at night sauvé', she wrote. ${ }^{144}$ 'Parti sauvé' was the expression used at the hospital to describe patients, cured or not, leaving for good without notice - a frequent occurrence not only at the maternity ward. The expression can be translated as 'departed to rescue oneself', which would concede that patients might feel better elsewhere and acknowledge their judgement on the chances of cure. The expression can be also understood as an emphasis of patients' lack of compliance; they 'departed and escaped'. Either translation becomes rather cynical in this particular case.

Two days later, Röthlisberger heard 'a tamtam from far and on the subsequent morning I learned that this poor woman had died, and that this was the reason for that tamtam', before concluding her account of the episode with the comment that 'it is a poor people.' ${ }^{145}$ Wildikann described the same incident in more dramatic detail:

We - all three physicians - then talked at the relatives for hours (in the true sense of the term) in order to receive permission for doing surgery, but in vain! The reply of the husband was: 'I prefer that my wife dies in the village without operation. ${ }^{146}$

Wildikann emphasized that this was the village where 'palm wine poisoning frequently occurred'. She ended the story writing that 'one day later, people told us that the woman died in great pain'. Wildikann then asked Schweitzer if he believed that 'in such cases, one had to force people. In Europe there are enough cases in which social welfare has to intervene and in which even

143 Goldschmid to Schweitzer, 21 December 1934, AMs. The woman died in February 1935. She had been well for weeks, but then her overall condition deteriorated, and she repeatedly vomited roundworms. See: Goldschmid to Schweitzer, 12 February 1935, AMs.

144 Röthlisberger to Schweitzer, 25 November 1936, AMs.

145 Ibid.

146 Wildikann to Schweitzer, 25 November 1936, AMs. 
parents were put under tutelage if they resist better knowledge and judgement and we also have a welfare mission here.'147

Röthlisberger focused her account on the 'Tamtam', a recurrent trope in the writings of hospital staff that seemed to provide them with particular fascination. Along with 'palavres', this drumming was depicted as typically local. Wildikann, in contrast, framed her version of the story around her medical duties: obtaining relatives' permission for the operation, mentioning in a somewhat derogatory manner the frequent episodes of poisoning in the village to emphasize the supposed backwardness of the woman's community, and ultimately reflecting on the ethical responsibility that she believed would even justify coercion. Above all, both of these medical practitioners portrayed African men as uninformed decision-makers - without denying that these also existed in Europe - and Gabonese women as passive victims.

In 1962, Dr. Müller claimed that, 4.2 percent of all deliveries at the hospital were cesareans. According to him, this number was distorted because the neighboring government hospital, which recorded a similar number of births, would not perform the intervention and sent all complicated cases to Schweitzer's hospital. Müller argued that most of the cesareans were performed due to pelvis constriction. To clarify this, he had the pelvises of 288 women measured, with the result that 22 displayed 'extreme values'. Three of them had to undergo a cesarean, which amounts to 13 percent. Thus, this very small sample shows that the likelihood of women diagnosed with pelvis constriction to deliver their babies by cesareans was indeed considerably higher than for those without. ${ }^{148}$ In this study, Müller did not blame local maternal ignorance for the high rate of cesareans, but cited the natural cause of pelvis constriction.

Table 3 illustrates that the ratio of cesareans to normal deliveries at the hospital was often significantly higher than during Müller's time; our admittedly small set of evidence suggests that it could reach over 10 percent. There are no numbers for Gabon for the years after independence. Detailed records for the Albert Schweitzer Hospital for the 1950s are also missing. This has resulted in a data overlap of only two years, during which the total number of births at maternity wards was still very low and figures might not be representative for later years. This extremely small sample suggests that cesareans were performed at the Albert Schweitzer Hospital much more frequently than at government hospitals.

Accounts of complicated deliveries, including those that involved craniotomies and cesareans, are only to be found in private letters. Schweitzer and his

147 Ibid.

148 Müller, '50 Jahre Albert-Schweitzer-Spital', 27. 
TABLE 3 Cesareans as a percentage of total deliveries (number of cesareans) ${ }^{\mathbf{a}}$

\begin{tabular}{cccc}
\hline Year & AEF & Gabon & $\begin{array}{c}\text { Albert Schweitzer } \\
\text { Hospital }\end{array}$ \\
\hline 1953 & $0.9 \%(147)$ & $0.6 \%(7)$ & $7.1 \%(5)$ \\
1954 & $1.5 \%(277)$ & $2.0 \%(32)$ & $5.4 \%(4)$ \\
1955 & $1.9 \%(272)$ & $2.8 \%(57)$ & \\
1956 & $2.0 \%(388)$ & $2.7 \%(59)$ & \\
1957 & & $1.9 \%(55)$ & \\
1958 & & & $10.2 \%(18)$ \\
1959 & & & $10.8 \%(21)$ \\
1960 & & & $7.2 \%(23)$ \\
1961 & & & $4.2 \%(15)$ \\
1962 & & & $7.1 \%(11)$ \\
1963 & & & \\
1964 & & & \\
\hline
\end{tabular}

a The numbers for AEF and Gabon are taken from the annual reports of the Service de Santé for AEF, ZK 005-93 (1952-53), ZK 005-16 (1954-55), and ZK 005-95 (1955-56), SHD. For 1957, I used the annual report for Gabon, ZKo05-005, SHD. The figures for the Albert Schweitzer Hospital are taken from the birth protocols. See: $\mathrm{L}-\mathrm{P}-\mathrm{A} \mathbf{1}-8$, AMs.

personnel unknew these practices and avoided discussing them in publications, which parallels their silence on the high prevalence of venereal disease in Gabon. They instead focused on the ignorance of Africans in matters of maternity care, thus underlining the hospital's self-proclaimed savior role.

The accumulation of accounts on complicated deliveries and the lack of updates on or interest in delivery numbers illustrate that personnel at the hospital perceived obstetrics as one of many medical services on offer. They did not connect it with a wish to increase the pool of African labor or domesticating African women to bring about their conversion to Christianity and adherence to the customs and values of 'European civilization'. In this manner, Schweitzer and his staff displayed a remarkable ignorance of influential colonial discourses behind maternity care. Unknowing this important part of their own medical culture, staff members constructed maternity care as a simple and purely medical service. A key question arising from these considerations is whether Africans also perceived giving birth at the Albert Schweitzer Hospital in this manner.

It is doubtful that there was an equivalent to the notion of a 'simple and purely medical service' in local conceptions of healthcare, as I have outlined in 
the Introduction. Indeed, this might be especially true for childbirth practices, in which so much cultural knowledge and meaning were embedded. Colonial government and missionary programs frequently targeted intimate spheres of African life in their zeal to reform diet, hygiene, or sexual practices while fighting the spread of sexually transmitted diseases. ${ }^{149}$ At Schweitzer's hospital, on the other hand, personnel participated in no community outreach programs and had only a limited pedagogical mandate. This meant that only women who wanted to give birth in a hospital made use of the obstetrical services that Schweitzer and his staff offered; nevertheless, these were still as much in demand as those of the government hospital across the river.

Even though, as I have demonstrated, hospital births were in some ways compatible with local practices, their numbers rose slowly until they eventually became more accepted due to external push factors, such as the requirement to obtain an official birth certificate or the fact that families received a payment when mothers gave birth in hospitals. Murray Last has argued that 'people's disinterest in medicine is an important medical phenomenon'; patients normally do not care how a medical system works. According to his observations in Hausaland, patients did not 'switch codes' when going from one healer or doctor to another; instead, they 'simply switch(ed) off'. 150 When it came to childbirth, Gabonese women were not willing or able to do either. They did not switch codes by coming to the hospital, presumably because they did not switch off and did care about the meanings and customs attached to deliver a baby.

These observations suggest that childbirth was not easily medicalized in Gabon. Elsewhere on the continent, the medicalization of maternity care occurred during the interwar period. ${ }^{151}$ Where this was the case, for instance in South Africa, it usually occurred due to the willingness of and demand from local mothers. ${ }^{152}$ African midwives played a crucial role in fostering this acceptance, because they were able to merge different kinds of knowledge in a culturally meaningful manner. ${ }^{153}$ Generally, only certain segments of the population sought medical assistance during and after childbirth, often the

149 Bruchhausen, 'Practising Hygiene and Fighting the Natives' Diseases', 100; Hunt, 'Le Bebe en Brousse', 431; Summers, 'Intimate Colonialism'.

150 Last, 'The Importance of Knowing about Not Knowing', 403.

151 Hugon, 'L'historiographie de la maternité en Afrique subsaharienne', 5; Schler, 'Writing African Women's History with Male Sources'.

152 Klausen, Race, Maternity, and the Politics of Birth Control, 111.

153 Barthélémy, 'Sages-femmes africaines diplômées en AOF'; Van Tol, 'Mothers, Babies, and the Colonial State', 119 . 
Christianized elite. ${ }^{154}$ In this regard, given the numerous mission stations located in the vicinity of Lambaréné, it remains unclear whether the maternity ward at the Albert Schweitzer Hospital answered to or created a demand for its services.

As we have seen, Schweitzer and his staff presented maternity care as a strictly medical service. However, they shared many of the same assumptions on African maternal ignorance that were integral to the wider colonial discourses on depopulation and domesticity. Occasionally, these assumptions revealed themselves in an overt manner. In 1934, for example, Schweitzer wrote:

The presence of women with their newborns gives Miss Koch, who is in charge of this unit, an opportunity to work against the improper care of mothers and infants, which is causing such great suffering here. For example, the bathing of babies is misused. If they are ill, it can happen that they to endure long washings in the river, even in the morning and evening coolness, through which they of course loses more and more of their strength. ${ }^{155}$

Schweitzer blamed Africans for not possessing this knowledge, accusing them of simple not-knowing. Thirty years later, Dr. Müller expressed the same sentiment in slightly less harsh-sounding words. He explained that

the raising of the many premature infants places a heavy burden on the nurses: for weeks the nurses have to take these children into their rooms at night, as the mothers are often too unreliable to allow them to take care of them on their own. ${ }^{156}$

Despite his softer tone, Müller now accused the mothers not of not-knowing, but of willful neglect, of not wanting to know. In contrast, other members of staff still placed more emphasis on their supposed ignorance as a case of notknowing. Stocker noted in her diary how one mother was caring very well for

154 Kanogo, 'The Medicalization of Maternity in Colonial Kenya', 79; Hunt, A Colonial Lexicon, 226.

155 Schweitzer, 'Briefe aus dem Lambarene Spital Februar 1934', 4.

156 Müller, '50 Jahre Albert-Schweitzer-Spital', 29. 
her newborn, who had been born prematurely, and wished that all of them would comprehend it so well. 157

Nurses frequently resorted to sheltering premature infants in their bedrooms at night to monitor them closely (see Illustration 24 and 25). Not only did this place an additional strain on the nurses, but, more importantly, illustrated their belief in the mothers' ignorance. Jo Munz abandoned the practice after she had to keep five babies at the same time in her room. When she handed this task back to the mothers, she nevertheless emphasized that she would continue to maintain 'supervision'. ${ }^{158}$ Important to underline here again is that this distrust of maternal abilities was not a uniquely colonial attitude.

From the point of view of the European personnel at the hospital, one of the main signs of African ignorance in matters of childbirth was mothers' frequent application of what became known as 'médicament indigène'. Substances, mostly herbal, found in arriving pregnant women's genital areas were a recurring concern for staff in the maternity ward. In 1936 for example, Röthlisberger wrote to Schweitzer after a series of difficult deliveries, wondering what they could do 'against the terrible superstition of the blacks and against the Médicament Indigènes?'159 Thereby she connected the use of such substances with the African worldview, which the European nurse considered backward and ignorant of proper medical practice.

One of the main worries that doctors and nurses had about médicament indigène was medical, namely that they would cause infection. In 1932, the wife of a catechist came to deliver her baby at the hospital. According to the nurse Lies Bonnema, Dr. Barend Bonnema's wife, the pregnant woman had had an opening of six centimeters for two days. When, on a ward round, they discovered her with 'much Medicament indigène in the vagina, my husband did not want to wait longer, as he feared an infection'. A biomedical solution followed: 'in lumbar anaesthesia he then applied the forceps and the baby came well and happy and cried immediately. Without having had a fever, the woman happily left with her boy on Sunday', Bonnema wrote. ${ }^{160}$ Thirty years later, Jo Munz also voiced surprise that there had not been more infections due to médicament indigène. ${ }^{161}$ As we have seen, this absence of infections on African bodies is a recurring trope in hospital sources, for example in relation to patients with a surgical wound.

157 Stocker, 'Diary 1961-63', 35-38.

$15^{8}$ Munz-Boddingius, 'Meine Chance und Freude, Hebamme in Lambarene gewesen zu sein', $66-68$.

159 Röthlisberger to Schweitzer, 15 August 1936, AMS.

16o Bonnema to Schweitzer, 18 December 1932, AMs.

161 Interview Munz and Munz. 


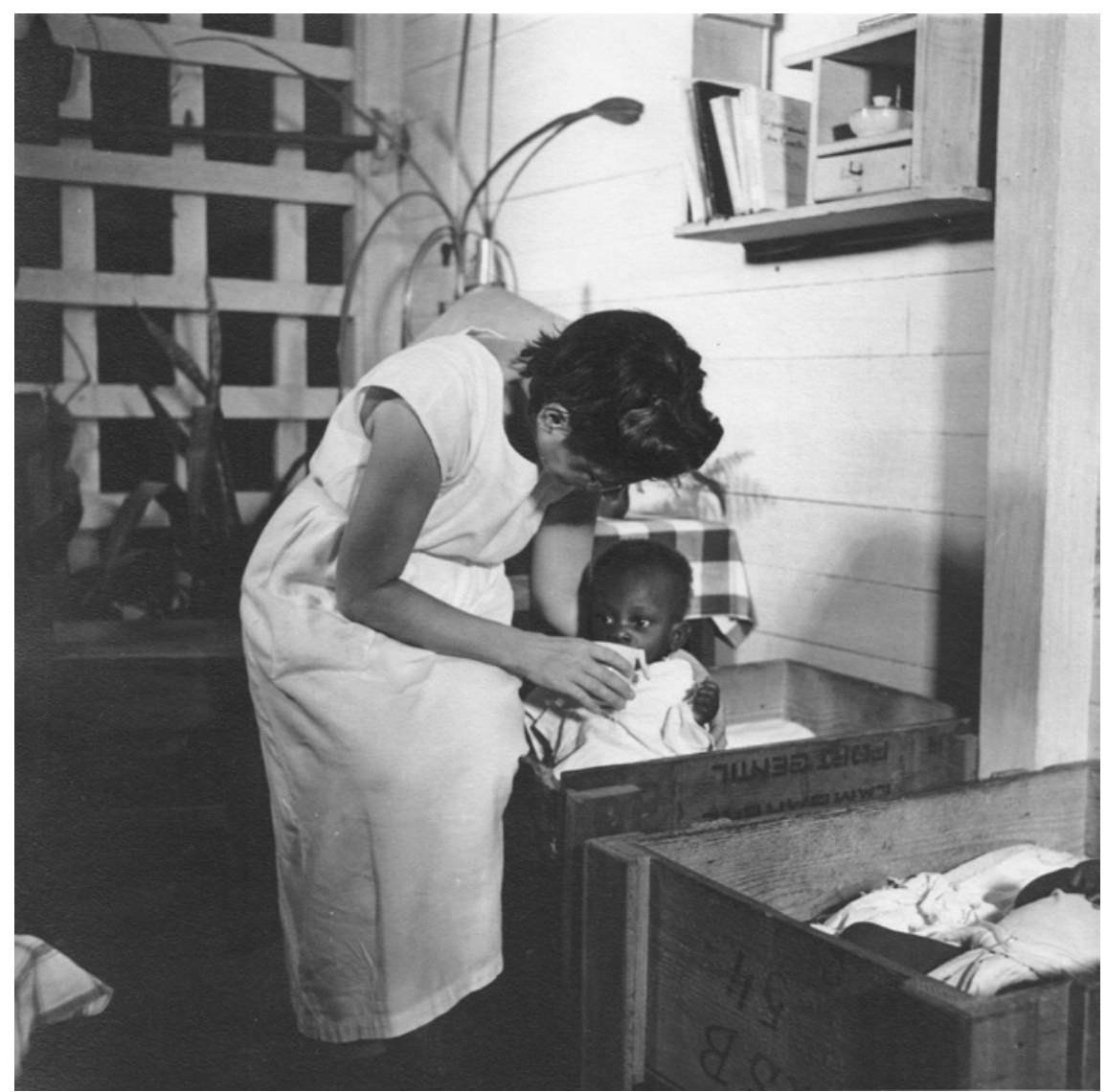

ILLUSTRATION 24 The nurse Irmgard Zinser has at least two babies in her room, ca 1951 (C) ARChives CENTRALES ALBERT SCHWEITZER GUNSBACH

Another medical problem associated with médicament indigène was the difficulties it posed to diagnosis. One of the few very detailed cases recorded in the birth protocols illustrates this. In July 1941, the midwife noted:

It is not possible to determine whether there is eclampsia or drug poisoning (médicament indigène). In fact, the woman's relatives, since she has been in labor for $2-3$ days, fed her with strong indigenous medicines until she passed out. ${ }^{162}$

162 This account is from the first volume of birth protocols that has survived. It covers the period from May 1937 to December 1941. The cited delivery took place on 25 July 1941. The nurse Maria Lagendijk and Dr. Anna Wildikann were working in the maternity ward at 


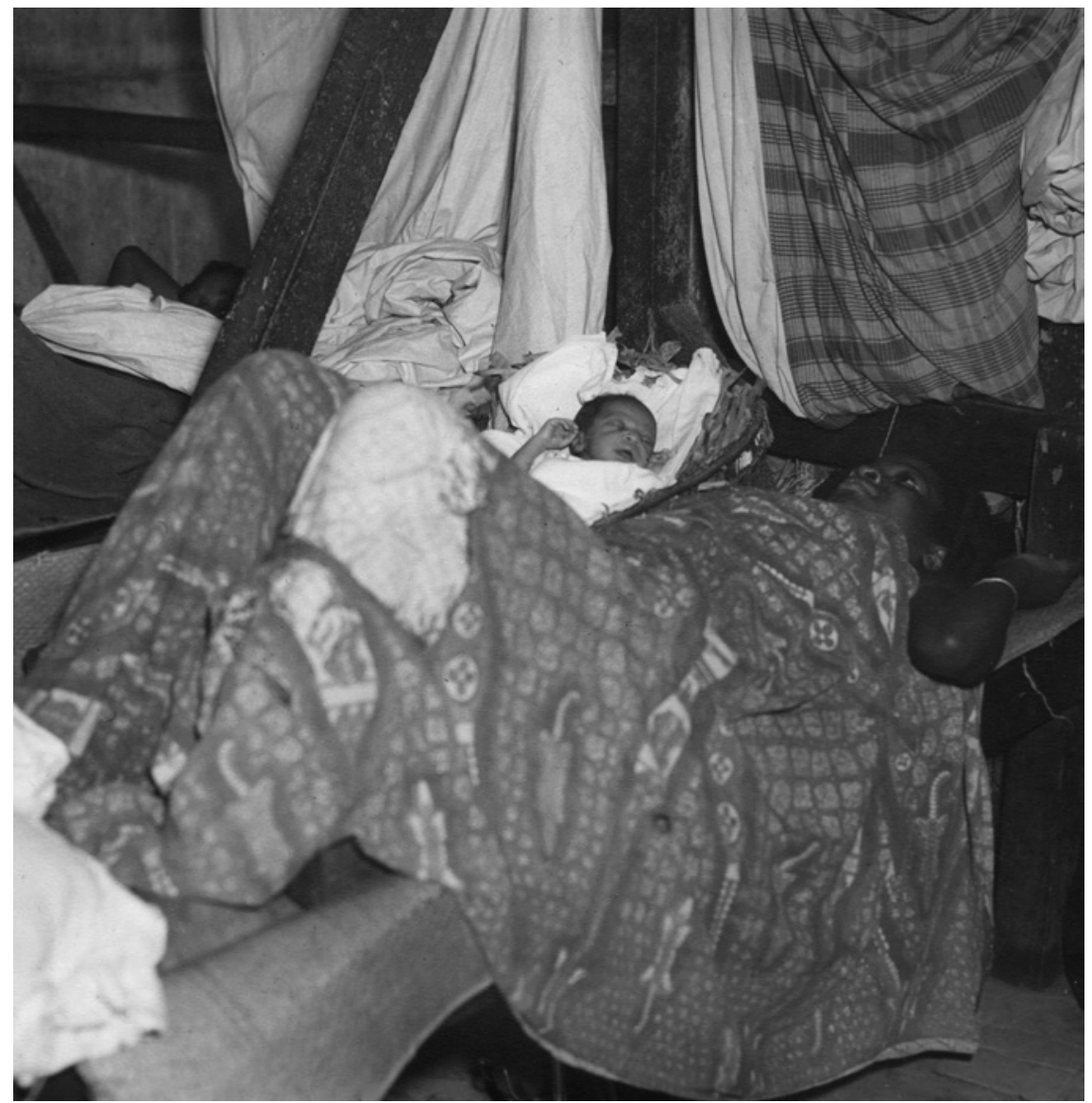

ILLUSTRATION 25 A mother with her baby in the bed, undated

(C) ARCHIVES CENTRALES ALBERT SCHWEITZER GUNSBACH

They were about to proceed with a cesarean, when suddenly the infant's head appeared. After a difficult yet successful delivery in which reanimating measures had to be applied, the baby died two hours later due to severe bleeding. In this case, médicament indigène had been swallowed rather than applied locally. The detailed description suggests that the nurse sought to blame the médicament indigène, and with it ultimately the ignorance of the mother's relatives, for the death of the baby. Just as in the previous example cited above, the mother herself is depicted as a rather helpless victim.

the time. From the handwriting, it appears that Lagendijk recorded the above description. See: $\mathrm{L}-\mathrm{P}-\mathrm{Al}$, AMS. 
Sometimes staffs were more forthright in attributing deaths to the application of médicament indigène. In 1936, Dr. Wildikann wrote of a pregnant woman who had died a few hours after arriving at the hospital. Wildikann added that the woman had been 'too badly treated with Medicaments indigens, e.g. the eyes, into which a mixture of lemon juice, piman, and salt had been put, were like burned out'.163 It is worthwhile pursuing how Schweitzer reported Wildikann's account in the leaflets that he sent to supporters in Europe. In October 1936, he wrote:

Miss Dr. Wildikann tells me of several cases in which black women in childbed, brought to the hospital, had previously been treated with medicines of the natives and thus endangered their lives. One of them had been treated by putting acidic substances in her eyes so that the eyesockets looked like burned out. What suffering must she have endured before she finally arrived here?164

The rather common lemon juice, salt, and pepper mixture thus became an exotic and dangerous acidic substance. As observed earlier, Schweitzer did not explicitly mention the death of an individual woman, but wrote of a general danger to life, reluctant to overly shock his readers. The picture that Schweitzer conveys of his hospital here is that of a place of shelter, or even salvation, where women who had suffered terribly by being unnecessarily treated with life-threatening substances by ignorant practitioners would find their sanctuary. Modern biomedical know-how would thus heal wounds that had been inflicted by what were considered primitive methods. However, Schweitzer offered his refuge only to those who sought it; he did not seek to counter supposed ignorance in a proactive way.

While the doctors considered the use of médicament indigène as proof of African ignorance, they remained largely ignorant about the components of these substances. Dr. Wildikann, for example, wrote to Schweitzer in July 1936, reporting that a delivery had been successful; 'even though this woman too had been treated with médicaments indigens (from vagina and anus I pulled out rags soaked in who knows what!). ${ }^{165}$ Even the protocols did not offer more specific details. In July 1959, a midwife noted that a woman had been 'brought in from village with retained products'. These were then expelled under anesthesia, and

163 Wildikann to Schweitzer, 18 June 1936, AMs.

164 Schweitzer, 'Briefe aus dem Lambarene Spital Oktober 1936', 2.

165 Wildikann to Schweitzer, 19 July 1936, AMs. 
the baby was delivered easily. In 1963, Dr. Müller described Gabonese deliveries to a specialist medical readership, writing of a 'spice':

A strong spice is then administered per orally and locally against secondary contractions. The spice is given in high amounts and strong concentrations. The already existing edema of the cervix and vulva is intensified by vaginal application. Such unfortunate cases are occasionally brought to hospital, while numerous vesicovaginal fistulas are signs of the other cases. $^{166}$

Besides Müller's indifference to the exact composition of local medication, his use of biomedical language and invocation of indirect evidence, the fistulas, to supposedly prove African ignorance are notable. This example demonstrates that the question of ignorance is also one of perspective. From the point of view of European physicians, the exact composition of médicament indigène was unimportant. Its effects on the body and its functioning were considered much more significant.

However, staff's ignorance on the composition of médicament indigène was not complete. Jo Munz believes it was 'chili powder'.167 In the already mentioned case from the 1941 birth protocols, the term 'indigenous medicines' was marked with an asterisk and defined as 'Cambo-Cambo-leaves as infusion,',168 a deviation from its typical description as a vaginal application in hospital- and non-hospital-related sources. In as early as 1910, Tessmann described the childbirth process in Fang society, remarking that 'of course it does not go without medicine. This involved the juice of specific plants being trickled into the vagina. The liquid being 'slippery, "smooth"' was thus to guarantee the 'smooth completion of the process.' 169

European medical staff at the Albert Schweitzer Hospital was ignorant about the application of such plant liquids, usually reporting the use of a powder or,

166 Müller, '5o Jahre Albert-Schweitzer-Spital', 25-26.

167 Interview Munz and Munz.

168 Rapoonda-Walker and Sillans write that the tree Xylopia brieyi was referred to as Kambogambo in Mitsogo. This tree is closely related to the one that provides what is commonly known as 'Grains of Selim' or 'African Pepper', seeds that were used as a spice, but also as a stimulant. Once decocted, its leaves were used to treat rheumatisms and as an emetic. There were numerous other plants used for the same purpose. See: Raponda-Walker and Sillans, Les plantes utiles du Gabon, 72.

169 Tessmann, Die Pangwe, 2:275. Tessmann lists this juice as coming from the following plants: Cephalonema polyandrum, Cucurbitaceae, Fleurya aestauans, Urticaceae. 
more rarely, a concoction to drink. In their 1961 book 'Les plantes utiles du Gabon', André Raponda-Walker and Roger Sillans list six plants that were regularly administered to women shortly after they gave birth. ${ }^{170}$ Most of these natural remedies were taken orally; the authors do not mention any powders and recount only one vaginal application. ${ }^{171}$ Three of these plants were also used to treat gonorrhea, which was of great concern and for which the application of medication as enemas was common. ${ }^{172}$ Given the high prevalence of the disease, it is not unlikely that women who arrived at the Albert Schweitzer Hospital with médicament indigène in their vaginas had used this to treat gonorrhea. Raponda-Walker and Sillans also list sixteen plants that women took to relieve pain or nausea during pregnancy. These too were usually consumed orally, frequently together with peanuts, ${ }^{173}$ a combination which suggests that the latter were considered a key element in a pregnancy diet.

The dietary habits of mothers and infants were taken by Europeans at Schweitzer's hospital as another sign of African ignorance in the area of childcare. In 1931, Schweitzer summarized his view on the issue as follows:

It is well known that women of primitive peoples do not breast-feed the child of a deceased woman, because in their superstition they believe that they are thereby falling under the power of the evil spirit which has killed the other woman. ${ }^{174}$

170 The subtitle of the book is 'essai d'inventaire et de concordance des noms vernaculaires et scientifiques des plantes spontanées et introduites, description des espèces, propriétés, utilisations économiques, ethnographiques et artistiques'. It was first published at Lechevalier in Paris. I am using a facsimile, reprinted in 1995 by the Fondation Raponda-Walker in Libreville.

171 Raponda-Walker and Sillans, Les plantes utiles du Gabon. Concoctions could consist of the leaves of a plant (in the case of Crotalaria glauca, a shrub, 249), its latex (Lecomtedoxa klaineana, 392), or its 'hearts' (Aframomum giganteum, from the ginger family, 427). It could also be a mix, (see for instance Homalium letestui and Piper guineense, $383^{\mathrm{f}}$ ). In addition, Entada gigas (monkey ladder) was used for therapeutic baths or as enemas (242).

172 These were Entada gigas, Crotalaria glauca, and Piper guineense (see above footnote). In total, the authors list thirty-two plants that have been used to treat gonorrhea.

173 The authors mention the following medicinal plants whose cooked leaves pregnant women ate together with peanuts: Culcasia scandens (a climbing plant, 95), Acanthus montanus (Bear's Breech, 39), Barteria fistulosa (also important in female initiation rites, 345), Bertiera racemosa (a flowering plant, 360 ), Fleurya podocarpa (also important in female initiation rites, 420), and Lygodium microphyllum (the ornamental climbing maidenhair fern, 439).

174 Schweitzer, 'Briefe aus dem Lambarene Spital Pfingsten 1931', 8. 
Numerous contemporaries shared this understanding into the $1950{ }^{0 .}{ }^{175}$ Most agreed that Gabonese mothers usually breastfed their children for about two years (see Illustration 26 ). ${ }^{176}$

According to biomedical personnel of the 1930s, breast milk was the ideal diet for babies. Such promotion occurred in other parts of Africa at the same time, while in Europe breast milk had been endorsed as the best way to feed babies since the beginning of the twentieth century. ${ }^{177}$ Sporadically in the 1930s, staff at the Albert Schweitzer Hospital had managed to obtain breast milk from African mothers. Dr. Barasch wrote to Schweitzer about a European newborn, whom he had fed first with the milk of the wife of the auxiliary Dominique Bouka and then with milk from another African woman, gradually adding more and more manufactured milk until he omitted breast milk entirely after three weeks. ${ }^{178}$ The nurse Alice Weber reported about half a year later that a European family had brought their eight-week-old baby to be treated for malaria. The doctors successfully treated the child with quinine infusions, blood transfusions, and the milk of African women, without specifying how it was obtained. ${ }^{179}$ These instances illustrate the pragmatic approach adopted at the hospital and modify the picture of colonial maternity programs that were, in the words of Nancy Hunt, 'permeated with a racism intent on protecting European children from African hands'. 180

For orphaned babies who were placed in the hospital's care, often brought by desperate fathers, nurses aimed to substitute mother's milk with goat's milk and imported condensed or powdered milk. In 1933, the hospital's goats provided a fifth of its total milk supply. ${ }^{181}$ During World War Two, staff had to abstain from drinking goat's milk because Schweitzer wanted to reserve it for babies. ${ }^{182}$ At that point, Joy and Arnold blamed an unspecified maternal ignorance for the frequent need for hospital staff to feed babies at the hospital. In the caption of a photograph in their book, they explain that the mother

175 Alexandre and Binet, Le groupe dit Pahouin, 92; Lavignotte, L'évur: croyance des Fañ du Gabon, 82 .

${ }_{17}$ They were also claimed to be sexually abstinent during this period. See: Joy, Arnold, and Schweitzer, The Africa of Albert Schweitzer, 39; Naegele, 'Rapport Medical sur l'HAS 1951', AMs; Tessmann, Die Pangwe, 2:276. Only Fernandez claimed that infants were weaned in their third or fourth years. See: Fernandez, Bwiti, 199.

177 Dreier, 'Europäisch gebären', 164; Marland, 'Childbirth and Maternity', 561; Wylie, 'The Ignorance of Mothers and the Health of Children in 2oth Century Pondoland', 109.

178 Barasch to Schweitzer, 15 December 1935, AMs.

179 Weber to Schweitzer, 18 July 1936, AMs.

180 Hunt, 'Le Bebe en Brousse', 415.

181 Schweitzer, 'Briefe aus dem Lambarene Spital Juli 1933', 7.

182 Schweitzer to Hume, 23 December 1940, AMs. 


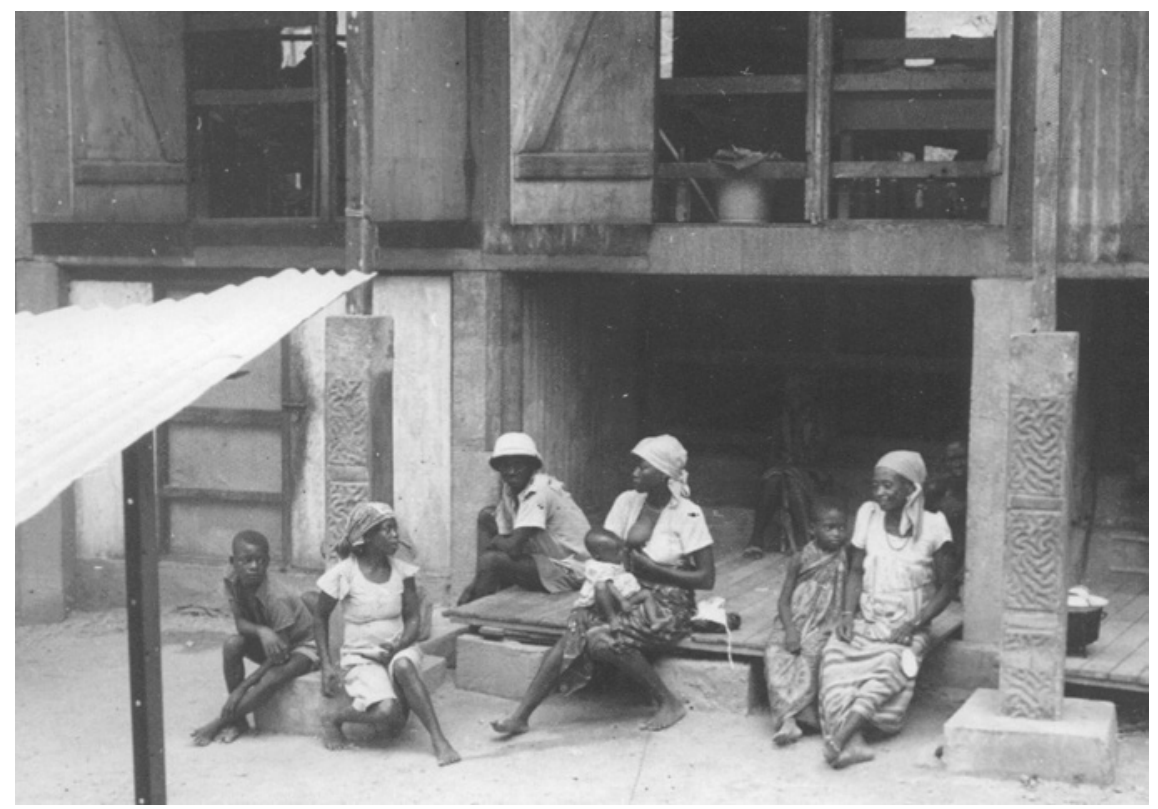

ILLUSTRATION 26 One of the very few pictures of a mother breast-feeding, undated (C) ARCHIVES CENTRALES ALBERT SCHWEITZER GUNSBACH

depicted 'is unable to nurse her baby adequately, so she has brought her child to the Hospital for help'. Their solution was simple: 'The nurses prepare a special formula with powdered milk from the United States. Mother and child will stay in the Hospital until the baby is six months old and can take soft foods.' ${ }^{183}$

Some staff blamed the local environment, not African ignorance or superstition, for fathers not being able to feed motherless babies. Writing about the 1930s, the nurse Marie Woytt-Secretan explained this perspective:

In the past, if a mother died giving birth, the child was also condemned to death, because there is no milk in the whole country. Cows do not find food in the jungle and also succumb to sleeping sickness. [...] But since Dr. Schweitzer has been working in the country, the fathers have brought such babies to the hospital. Although they often arrive almost famished, we manage to save most of them and the canned milk from Europe does them good. ${ }^{184}$

183 Joy, Arnold, and Schweitzer, The Africa of Albert Schweitzer, 133 .

184 Woytt-Secretan, Albert Schweitzer baut Lambarene, 102. 
Once again, the trope of the hospital as a final refuge, a place of salvation, emerges. African children and their fathers are depicted as victims of the hostile vegetation and the tsetse fly. There is no pedagogical dimension in this account: like the mothers in the previous extract, widowers could solve the problem by bringing their children to the hospital, which possessed the necessary capacity and resources to obtain a substitute for mother's milk.

Occasionally, infants would be fed with more solid foods at the hospital. In 1936, Röthlisberger reported to Schweitzer that in addition to condensed milk, oatmeal gruel had been given to three-week-old babies, an approach that, according to her, had proven successful before. ${ }^{185}$ In contrast, two years earlier, Schweitzer had emphasized the supposed ignorance of a mother, who had given birth in the morning by claiming that they 'found her busy feeding mush of rice to the world citizen who was only a few hours old!"186 Feeding was thus an area of improvisation where babies received what was available and where staff could not uphold control.

In the late 1950s and early 1960s, staff at the hospital continued to put effort into feeding babies with breast milk, but acknowledged their frequent use of substitutes (see Illustration 27). Dr. Mai noted in his 1956 diary that a 'diet without breast milk is much more difficult with black babies than with white babies and almost never succeeds'. ${ }^{187}$ Anderegg recalled that mothers would be kept at the hospital after a cesarean until it was certain that they could produce enough milk. ${ }^{188}$ In 1962 , Stocker tricked a group of mothers into providing additional breast milk to feed motherless infants, a request that they had previously refused. She told mothers of dysenteric children that the milk for the child is not good now, you have to empty everything.'189 According to Stocker, the amount of milk that she obtained under this false pretense was still insufficient; she emphasized that many babies would have died without canned milk. ${ }^{190}$

Not only were infants' diets a concern for hospital staff, but even more so were those of expectant mothers. Numerous pregnant women arrived in a state considered undernourished, and doctors worried about the effects that this would have on their babies. Mothers-to-be were thus provided with calcium to supplement their diets for much of the 1930s, an approach that was

\footnotetext{
185 Röthlisberger to Schweitzer, 15 August 1936, AMs.

186 Schweitzer, 'Briefe aus dem Lambarene Spital Februar 1934', 4.

187 The diaries of Hermann Mai are held at AMs.

188 Interview Elisabeth Anderegg.

189 Stocker, 'Diary 1961-63', 55.

190 Interview Marianne Stocker.
} 


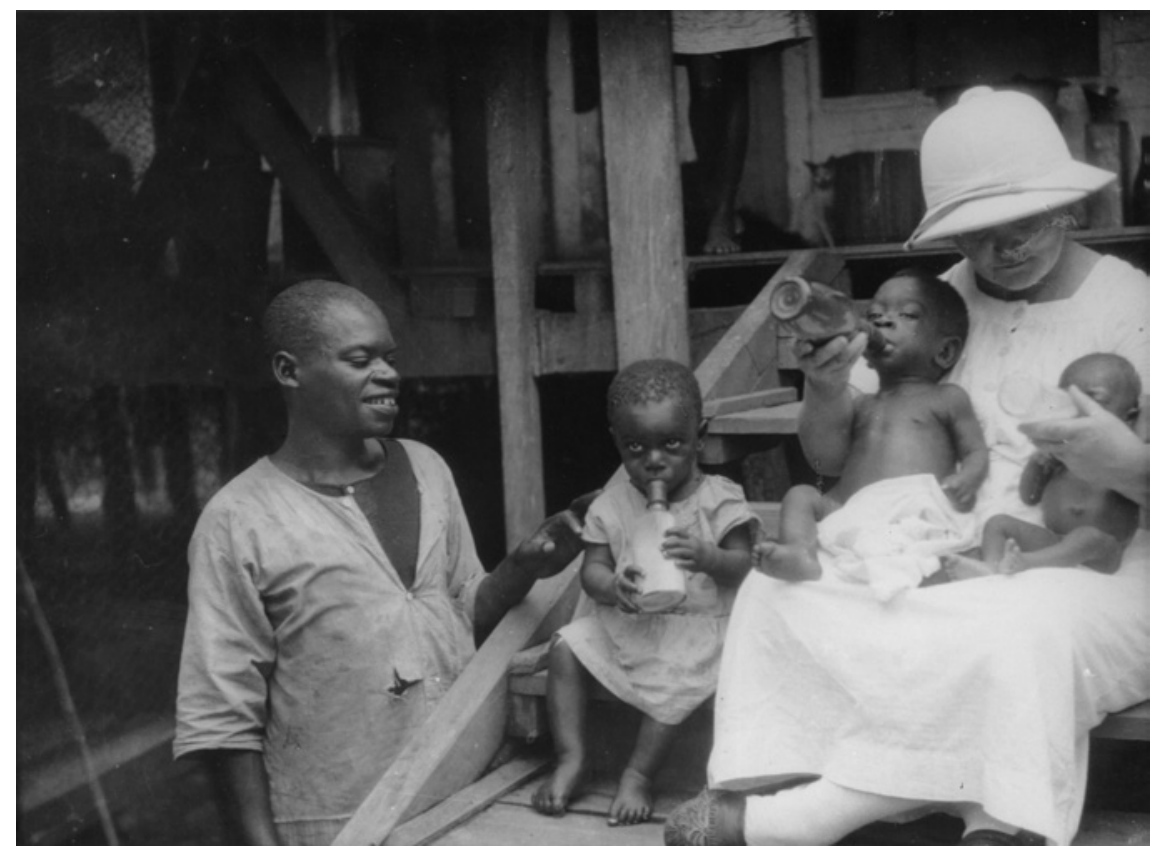

ILLUSTRATION 27 Gertrude Koch bottle-feeding, a father (?) watching, ca. $195^{\circ}$ (C) ARChives CENTRALES ALbERT SCHWEITZER GUNSBACH

thought to make their babies stronger and more vigorous. ${ }^{191}$ In 1936, Wildikann proudly reported to Schweitzer that 'our calcium-babies are splendid specimens', ${ }^{192}$ in the process invoking a somewhat dehumanizing image. In 1953, however, Schweitzer noted in one of his notebooks that calcium rendered deliveries difficult, providing a short and rather unclear explanation in brackets: 'accumulation of calcium in the bones.' ${ }^{193}$ The practice of providing calcium as a supplement had thus came to an end, but the diets of pregnant women were still considered inadequate in the early 1960 . Here, however, the primary concern for hospital staff was still that of the health of the infant: Jo Munz, for example, claimed that expectant mothers' poor diets frequently led to premature deliveries. The solution, also noted in the birth protocols, resembled that

191 Schweitzer, 'Briefe aus dem Lambarene Spital Mai 1937', 3-4.

192 Wildikann to Schweitzer, 18 June 1936, AMs.

193 See the notebook '1953 Medizinische Notizen Lambarene', AMs. 
of the 1930s. Instead of a regular dose of calcium, pregnant women received iron and vitamins every morning at eight o'clock. ${ }^{194}$

One way to counter perceived ignorance was to educate women, especially concerning diet. However, unlike at other colonial hospitals and especially at missionary ones, ${ }^{195}$ neither Schweitzer nor any of his staff placed any great emphasis or attention on educating female patients in domestic responsibilities or 'proper' maternal practices during much of the study period. Instead, the focus of Schweitzer's 'civilizing mission' lay on manual and agricultural labor. It was thus left to Stocker to introduce what she claimed was the first 'maternity counseling' at the hospital, although she did note that some pedagogical measures had been implemented before her time. These included pregnant women who arrived at the hospital before their expected date of delivery being made to help in the laundry. According to Stocker, they also 'learned all sorts of things they should know for the care of their child'. She claimed that 'all this is only in its beginnings and should be expanded further. I think of some sort of maternity school. 196

Stocker introduced such a program during her second stay from May 1965. She organized this in loose cooperation with Dr. Munz; both wanted to leave Schweitzer out of its running because he was 'old and tired'. The lessons that it offered were mainly in 'diet and health', two areas in which Stocker and Munz had identified a supposed distinct lack of knowledge among local women. Pregnant women and those who had recently given birth at the hospital were thus taught, for example, to provide their children with more protein, such as eggs, milk, and fish. ${ }^{197}$ As with the vacuum extractor, this is another example of staff introducing a new practice without informing Schweitzer; in this case, a preventive one, contrary to the hospital's usual focus on curative medicine. The measures taken by Stocker and Munz in this regard resemble those discussed at the Geneva conference on the African child more than thirty years earlier, which ignored the political, social, and economic circumstances of mothers in the region. ${ }^{198}$

Stocker's efforts were not without precedent at the hospital. Erika Taap, an evangelical sister from the Berlin Mission who visited in August 1960, claimed

\footnotetext{
194 Munz-Boddingius, 'Meine Chance und Freude, Hebamme in Lambarene gewesen zu sein', 66.

195 Addae, The Evolution of Modern Medicine in a Developing Country, 230; Coghe, 'InterImperial Learning', 150; Hugon, 'La redéfinition de la maternité en Gold Coast', 157-58; Jennings, 'A Matter of Vital Importance', 246.

196 Stocker, 'Diary 1961-63', 7.

197 Interview Marianne Stocker.

198 Allman, 'Making Mothers', 1994.
} 
that an important practice in the maternity ward was the counseling of pregnant women. Depicting a more idealized process than that outlined above, she described how staff asked women to arrive 'some time before the delivery to get used to the hospital organization' and to stay 'after the delivery in order to learn under the eyes of the nurses and doctors how to properly care for their child. ${ }^{199}$ More than ten years earlier, Joy and Arnold also referred to an educational aspect of maternity care:

Mother and child will stay in the Hospital until the baby is six months old and can take soft foods. Meanwhile the staff will teach the mother how to make soup from bananas, and how to prepare rice, papaya and other foods for infant consumption. ${ }^{200}$

Given that at this time the number of deliveries at the hospital was rather low, it is unclear to what degree this was common practice. The quote certainly underlines the importance of dietary considerations in a more specific manner.

Staff members in the 1930 s did not mention pedagogic measures. They were, however, convinced that Africans were ignorant in matters of childbirth and childcare and sought ways to mitigate this supposed ignorance. For example, Lies Bonnema wrote in December that she kept 'to this principle: from the moment the contractions begin, I do not leave a woman alone for even a moment!'201 This was a command from Schweitzer himself. From Europe, he had written one of the very rare letters in which he voiced concern about the hospital's maternity services. To the physicians he explained how he wanted childbirth procedures to occur:

I don't know if, tired at the time of departure as I was, I ordered clearly enough that a nurse who watches over an expectant mother should not leave her (even if the delivery is not anticipated for several hours) without another nurse replacing her, even if it is only for the quarter of an hour for lunch or dinner! If you please inculcate this instruction to the nurse, in each case anew! It is that the expectant mother should not have the slightest uneasiness. I have told you on my departure that I want the doctor in charge of the delivery to stay within easy reach of the woman during the last hours and to sleep in the room next to her at night, in

199 Taap, Lambarener Tagebuch, 58.

200 Joy, Arnold, and Schweitzer, The Africa of Albert Schweitzer, 133.

201 Bonnema to Schweitzer, 18 December 1932, AMs. 
reference to a case that occurred years ago, when the doctor was not reachable for a birth. ${ }^{202}$

Schweitzer ultimately refers to a situation that had gone wrong years earlier to justify this command for upholding good medical practice and to prevent negligence from the side of his staff. Although he does not explicitly mention the ignorance of Africans and worries about their well-being, a clear mistrust in the abilities and knowledge of local mothers' shines through an order that strikingly resembles his instructions for control in the operating theater. In 1960 still, Schoenfeld reported that 'when labor was prolonged I would sleep on a table near the patient while Suzanne and the grandmother spread their mats on the floor.'203 Similar doubts about mother's abilities persisted until after the delivery of the baby, as we have seen in the case of nurses keeping premature infants in their rooms.

\section{7}

\section{Conclusion}

In 1936, Dr. Wildikann recorded a vivid account of an anecdote from the maternity ward that illustrates many of the issues raised in this chapter. In a letter to Schweitzer, she wrote of a pregnant woman who had accompanied her husband, who had come to the hospital to have his hernia repaired. The night after the man's operation, his wife had gone into labor. She then retreated into the 'bush, because she did not want any help from whites for her delivery'. Wildikann informed the auxiliary Ambroise Nyama, a 'fellow tribe member', of the incident, who managed to persuade the woman to return to the hospital. Wildikann described the subsequent delivery procedure as follows:

With tricks and cunning I managed to get the woman on the delivery table and to keep her on it during the whole process. If you did not hold her hands tightly, she tore herself away again and again, penetrated with monkey-like speed with one hand into the vagina and pulled at her uterus (no animal is so crazy!) in such a way that a severe bleeding was the result. $^{204}$

202 Schweitzer to Bonnema and van der Elst, 1 August 1932, AMS.

203 Schoenfeld, 'A Summer at Dr. Schweitzer's Hospital (Draft)', AMs, 17-18.

204 Wildikann to Schweitzer, 8 April 1936, AMs. According to Wildikann, the baby was perfectly healthy, but it took two days to control the bleeding. 
The coercive element of this intervention was exceptional for obstetrical practice at the Albert Schweitzer Hospital. Typically, procedures were not forced upon patients, as has been demonstrated in the cases of proposed cesareans that did not meet with patient consent. Wildikann's language is unusually harsh in this passage. She also takes the accusation of ignorance to the highest level: an animal would have acted more reasonably than the woman portrayed in the anecdote.

Wildikann's privately communicated account contrasts with the description that Barthélemy published thirty years later and quoted at the beginning of this chapter. He depicts cesareans as a routine procedure that occurred rather regularly, usually with a successful end result. He also acknowledges how strange the situation is for the woman, who nevertheless seems to quietly accept everything that is happening around her. Characteristically for a published account, mother and child are not pictured in an overly negative light or as suffering and vulnerable victims in a critical state. In private letters, however, the doctors often portrayed mothers, expectant and not, and her kin as primitive and ignorant.

Obstetrical services at the hospital were based on this premise that Africans were ignorant of proper biomedical childbirth and infant care practices. Doctors articulated supposed African ignorance in a more medicalized language, but nurses also expressed their frustration on the same topic. Infant and maternal diets, as well as the use of non-biomedical medicines during pregnancy, were taken as the main evidence of this ignorance. In most cases that were reported in detail, usually those that involved a difficult delivery or the discovery of the use of médicament indigène, it was not the mother who was blamed for her ignorance, but her relatives. Personnel were frequently confronted with practices that they considered ignorant, yet they did not choose to actively counter these; they unknew them. A strict staff recruitment and selection process, focused on personality traits rather than medical training, ensured this restraint, which was in accordance with the hospital's overall mission and vision.

Focusing on the many dimensions of (perceived) ignorance, this chapter has argued that the typical colonial explanatory frameworks for maternity services - depopulation and domesticity - were of little concern at the Albert Schweitzer Hospital. By ignoring these political, social, and economic justifications, staff constructed obstetrics as a simple medical service. They depicted the hospital as a place of universal refuge to which locals could flee to be saved from dangerous and unhealthy local practices. In the process, obstetrical personnel ignored details about how the delivery of babies occurred in the villages, while they took into account some of the preferences of African women on 
how to give birth. Nurses, midwives and doctors thus improvised during each delivery, for instance in regards to the presence of relatives or a woman's preand postnatal mobility. They reacted spontaneously to the practical challenges they faced, which varied from questions on how to feed women and infants to finding the most suitable way for resolving complicated cases. 